\title{
Factors Affecting the Synthesis of Cellobiose Lipids by Sporisorium scitamineum
}

\author{
Amira Oraby ${ }^{1,2}$, Nicole Werner ${ }^{2}$, Zehra Sungur ${ }^{1}$ and Susanne Zibek ${ }^{1,2 *}$ \\ ${ }^{1}$ Fraunhofer Institute for Interfacial Engineering and Biotechnology IGB, Stuttgart, Germany, ${ }^{2}$ Institute of Interfacial Process \\ Engineering and Plasma Technology IGVP, University of Stuttgart, Stuttgart, Germany
}

Cellobiose lipids $(\mathrm{CL})$ are extracellular glycolipids that are produced by many microorganisms from the family Ustilaginaceae. The sugarcane smut fungus Sporisorium scitamineum has been long known as a producer of the glycolipids mannosylerythritol lipids (MEL) and was recently described to additionally secrete $\mathrm{CL}$ as a byproduct. In fact, we identified 11 homologous genes in S. scitamineum by in silico analysis sharing a high similarity to the CL biosynthesis gene cluster of Ustilago maydis. We here report the first systematic cultivation of $S$. scitamineum targeting the synthesis of $\mathrm{CL}$ with high product titers and its transfer to the bioreactor. In an initial screening we examined different fermentation media compositions, consisting

OPEN ACCESS

Edited by:

Eric Déziel,

Université du Québec, Canada

Reviewed by:

Leonie Asfora Sarubbo,

Catholic University of Pernambuco,

Brazi

Bjorn Sandrock,

University of Marburg, Germany

*Correspondence:

Susanne Zibek

Susanne.zibek@igb.fraunhofer.de

Specialty section:

This article was submitted to

Industrial Biotechnology,

a section of the journal

Frontiers in Bioengineering and

Biotechnology

Received: 25 April 2020

Accepted: 13 October 2020

Published: 04 November 2020

Citation:

Oraby A, Werner $N$, Sungur $Z$ and

Zibek S (2020) Factors Affecting

the Synthesis of Cellobiose Lipids by

Sporisorium scitamineum.

Front. Bioeng. Biotechnol. 8:555647.

doi: 10.3389/fbioe.2020.555647 of a mineral salts solution with vitamins and/or trace elements, three carbon sources (glucose, fructose, sucrose), three $\mathrm{pH}$ values $(2.5,4.0,6.7)$ and three levels of $\mathrm{C} / \mathrm{N}$ values $\left(42.2,83.8,167.2 \mathrm{~mol}_{\mathrm{C}} \cdot \mathrm{mol}_{\mathrm{N}}{ }^{-1}\right)$ with urea as nitrogen source. A pH of 2.5 proved to result in the highest product titers. An increase of urea concentration from 0.6 to $1.2 \mathrm{~g} \cdot \mathrm{L}^{-1}$ had a positive effect on biomass formation, however the glycolipid formation was favored at a $\mathrm{C} / \mathrm{N}$ ratio of $83.8 \mathrm{~mol}_{\mathrm{C}} \cdot \mathrm{mol}_{\mathrm{N}}{ }^{-1}$, using $0.6 \mathrm{~g} \cdot \mathrm{L}^{-1}$ urea. Amongst the examined carbon sources, sucrose resulted in an increase in the secretion of cellobiose lipids, compared to glucose. Comparing different media compositions, vitamins were identified as not necessary for CL synthesis. We obtained a concentration of cellobiose lipids of $8.3 \pm 1.0 \mathrm{~g} \cdot \mathrm{L}^{-1}$ in shaking flasks. This increased to $17.6 \mathrm{~g} \cdot \mathrm{L}^{-1}$ in the $1 \mathrm{~L}$ bioreactor with additional feeding of carbon source, with a final purity of $85-93 \%$. As a side product, erythritol and mannosylerythritol lipids (MEL) were also synthesized. Via HPTLC coupled MALDI-TOF MS we were able to analyze the secreted CL structures. S. scitamineum produces a mixture of acylated low molecular weight D-glucolipids, linked to a 2,15,16-trihydroxy-hexadecanoic acid via their $\omega$-hydroxyl group (CL-B). The produced cellobiose lipids precipitate as needle like crystals at an acidic $\mathrm{pH}$ value of 2.5.

Keywords: cellobiose lipids, Sporisorium scitamineum, fermentation process, glycolipids, biosurfactant

\section{INTRODUCTION}

Cellobiose lipids (CL) are a group of microbial biosurfactants that are secreted as secondary metabolites by many microorganisms from the family Ustilaginaceae, with Ustilago maydis being the most examined producer of CL. They were first discovered in 1950 by Haskins while screening a wide range of fungi for their ability to metabolize glucose and agricultural wastes 
(Haskins, 1950). CLs are reported to have various antimicrobial and antifungal activities, as well as gelling characteristics, making them of high interest for application in cosmetics, as detergents, or fungicides (Haskins and Thorn, 1951; Puchkov et al., 2002; Cheng et al., 2003; Teichmann et al., 2007; Imura et al., 2014). Widely studied producers of CL besides Ustilago maydis are Anthracocystis flocculosa (formerly known as Pseudozyma flocculosa), Kalmanozyma fusiformata, Sporisorium graminicola, and Cryptococcus humicola, amongst others (Kulakovskaya et al., 2006; Golubev et al., 2008; Kulakovskaya et al., 2007; Teichmann et al., 2011a).

CLs are usually produced as a mixture of different acylated low molecular weight D-glucolipids, linked to a hydroxypalmitic acid via their $\omega$-hydroxyl group (Eveleigh and Dateo, 1964). Depending on the producing microorganisms, typical strainassociated structural varieties can be observed. $U$. maydis secretes a CL variant with binding a 15,16-dihydroxyhexadecanoic acid or a 2,15,16-trihydroxy-hexadecanoic acid fatty acid chain to the cellobiose CL-B. The fatty acids can further differ in the presence or absence of their hydroxyl group $\left(\mathrm{R}_{1}=\mathrm{H}\right.$ or $\mathrm{OH}$ ) or the length of the acyl chain at $2^{\prime \prime}$ position (Figure 1A; Spoeckner et al., 1999; Teichmann et al., 2007). An additional variant with an ester group is known as CLC (Spoeckner et al., 1999). A. flocculosa produces flocculosin, a CL that has an extra acetyl-group at $\mathrm{C}^{\prime \prime}$ position and whose cellobiose is esterified with 2-hydroxy-octanoic acid and acetylated at two positions (Teichmann et al., 2011a). C. humicola secretes a mixture of different types of CL with the bolaform 16-O- $\left(2^{\prime \prime}, 3^{\prime \prime}, 4^{\prime \prime}, 6^{\prime}\right.$-tetra-O-acetyl- $ß$-cellobiosyl)-2hydroxyhexadecanoic acid being the major product (Puchkov et al., 2002; Morita et al., 2011). In CL produced by K. fusiformata a 2,15,16-trihydroxypalmitic acid is linked to the cellobiose and 3-hydroxycaproic acid and acetic acid are linked as $\mathrm{O}$-acylic substituents, corresponding to the structure of CL-B produced by U. maydis (Kulakovskaya et al., 2005).

A gene cluster containing 12 open reading frames coding for enzymes needed for CL synthesis was first identified in U. maydis, proposing a biosynthesis route for CL (Teichmann et al., 2007). In U. maydis, the zinc finger transcription factor Rual regulates CL synthesis (Teichmann et al., 2010). The monooxygenase Cyp1 terminally hydroxylates the de novo synthesized precursor palmitic acid, while Cyp $2 \omega-1$ hydroxylates the 16-OH palmitic acid. The two glucose units of the sugar moiety are added by the glycosyltransferase Ugt1. Fas2 synthesizes the additional fatty acids and Uhd1 catalyzes their $\beta$-hydroxylation. The acetyltransferase Uat 2 transfers the shorter fatty acid to CL in $\mathrm{C6}^{\prime}$ position, while Uat1 acylates the C2" position in the cellobiose molecule. Ahd1, the $\alpha$-hydroxylase, catalyzes the hydroxylation of the palmitic acid. Finally CL is exported by the transporter Atr (Teichmann et al., 2007, 2011a). A highly similar gene cluster with 11 open reading frames was identified for A. flocculosa, thus suggesting a highly conserved biosynthesis pathway in both glycolipid producers (Teichmann et al., 2011a).

Sporisorium scitamineum (formerly Ustilago scitaminea) is another Ustilaginaceae species, that is known as sugar cane smut fungus (Braithwaite et al., 2004). Phylogenetic analysis revealed
Sporisorium reilianum as sister species, both branching early in the evolutionary history from U. maydis (Que et al., 2014). However, genomic characteristics like genome and gene size, GC content or number of exons and introns etc. are most similar to U. maydis (Que et al., 2014; Taniguti et al., 2015; Dutheil et al., 2016). Besides, encoded proteins in S. scitamineum show an average of $75.4 \%$ identity to proteins of $U$. maydis (Que et al., 2014), which confirms their relationship. S. scitamineum (NBRC 32730) was long known as MEL producer, another biosurfactant that is also produced by. U. maydis strains (Hewald et al., 2006; Morita et al., 2009a,b). In 2014 the first synthesis of CL by S. scitamineum (NCBI: txid49012) was reported, as a result of a wide screening of different Ustilaginaceae species for the production of value-added chemicals (Geiser et al., 2014). The produced structures are correspondent to CL variants produced by $U$. maydis (Deinzer, 2017). However, to our knowledge no further studies on CL synthesis by $S$. scitamineum are published, and the sequences of the CL biosynthesis cluster have not yet been described. While CL is of potential interest for application in various industrial sectors, as previously mentioned, fundamental research is still needed for a better understanding of factors affecting CL synthesis. A research gap is evident here.

Therefore, this paper aims to study S. scitamineum as a $\mathrm{CL}$ producer and analyse factors potentially important for CL synthesis. As $S$. scitamineum is closely related to $U$. maydis, we hypothesized that factors affecting its glycolipid production are similar. In order to gain a better understanding and to verify this hypothesis, the effect of $\mathrm{pH}$ value, carbon source and $\mathrm{C} / \mathrm{N}$ ratio as well as media composition on microbial growth and CL synthesis were examined. All these factors were reported to have direct effects on the produced amount of CL amongst the various producing microorganisms (Roxburgh and Spencer, 1954; Hammami et al., 2008; Günther et al., 2010; Liu et al., 2011; Zavala-Moreno et al., 2014). Furthermore, most studies related to microbial CL synthesis focus on shaking flask cultivations, with only limited publications reporting a CL production in bioreactors, with titers varying from 13 to $33 \mathrm{~g} \cdot \mathrm{L}^{-1}$ (Roxburgh and Spencer, 1954; Frautz et al., 1986; Liu et al., 2011; Morita et al., 2011). To generate more process knowledge for CL fermentations in bioreactors, we further present the first cultivation of S. scitamineum for CL synthesis in a fermenter.

\section{MATERIALS AND METHODS}

\section{Protein Sequence Homology Analysis of S. scitamineum}

Protein sequences of the $U$. maydis (NCBI: txid237631) CL gene cluster were used to identify open reading frames and find homologous sequences in the S. scitamineum (NCBI: txid1447027) annotated genome (ASM90000236v1) (Dutheil et al., 2016) by alignment analysis via BLAST. This strain is from the same clade as used for our experiments. Amino acid sequence similarities and identities were calculated using the Needle EMBOSS software (Madeira et al., 2019). 


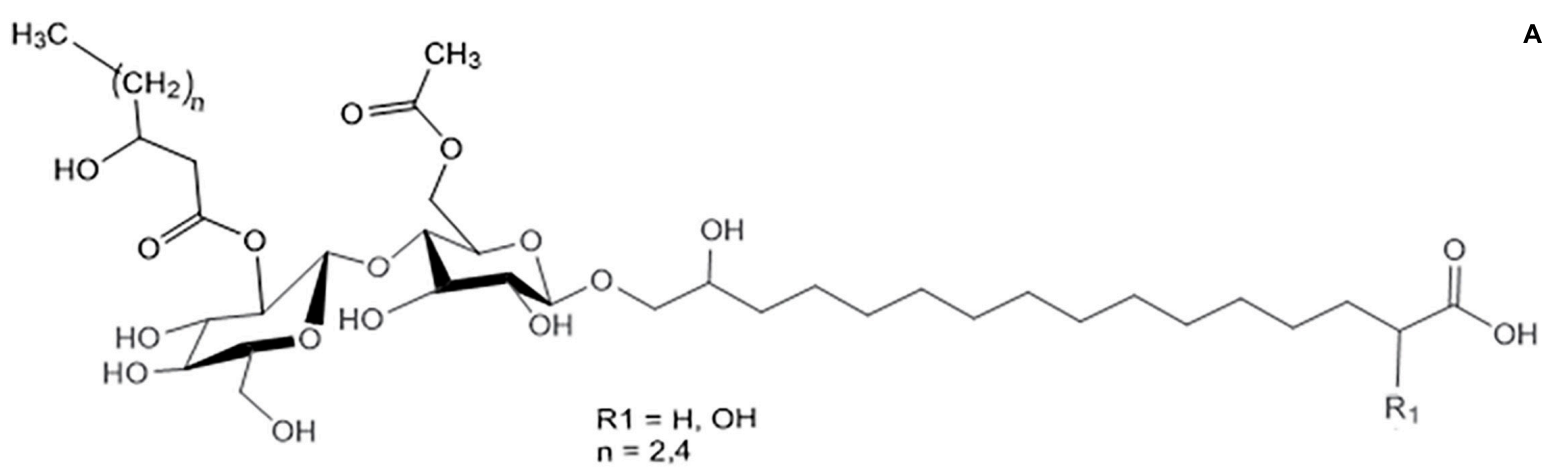

B
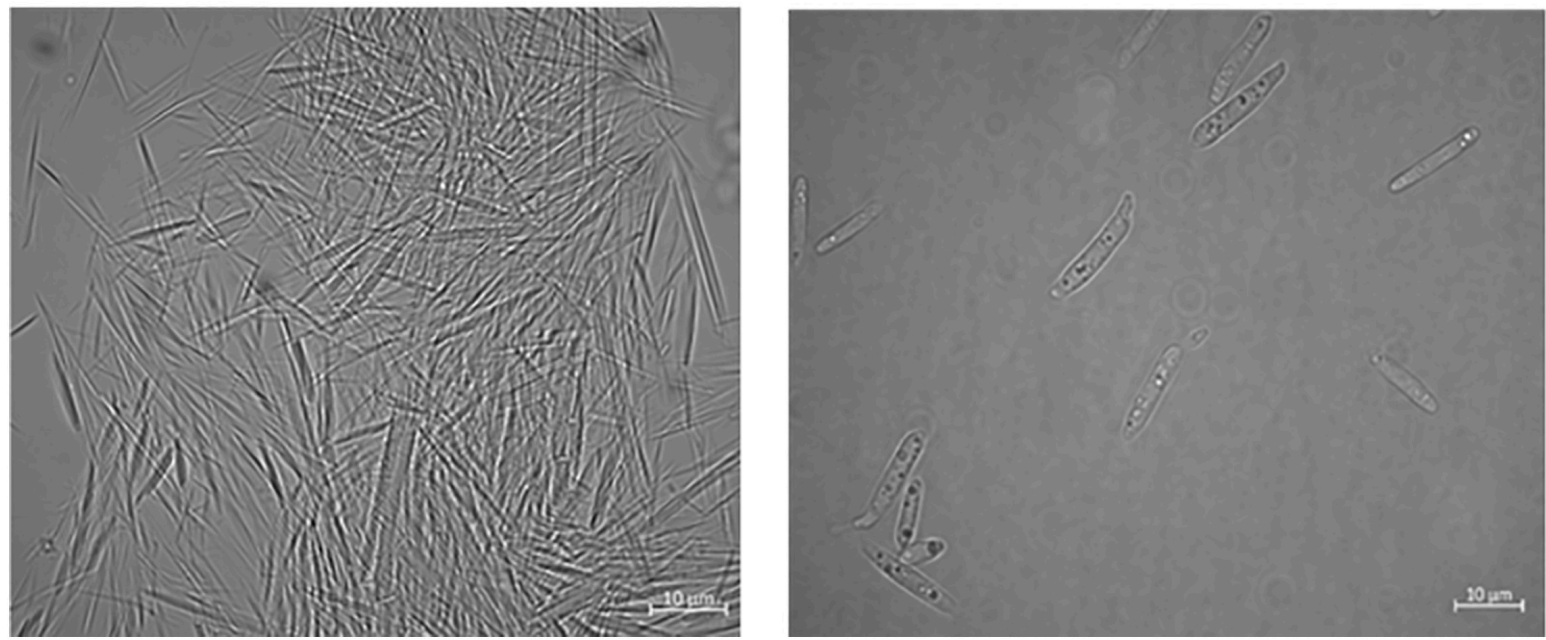

FIGURE 1 | (A) Structure variants of CL-B (Spoeckner et al., 1999). (B) Microscope images of precipitated needle like CL crystals, secreted by S. scitamineum. (C) S. scitamineum grown in complex YM medium without CL crystals.

\section{Strain and Seed Culture}

Glycerol cryo cultures of the strain Sporisorium scitamineum (Ustilago scitaminea) DSM 11941, obtained from the German Collection of Microorganisms and Cell Cultures (DSMZ), were stored at $-80^{\circ} \mathrm{C}$ and used to streak agar plates containing YM medium ( $10 \mathrm{~g} \cdot \mathrm{L}^{-1}$ glucose, $5 \mathrm{~g} \cdot \mathrm{L}^{-1}$ peptone, $3 \mathrm{~g} \cdot \mathrm{L}^{-1}$ malt extract, $3 \mathrm{~g} \cdot \mathrm{L}^{-1}$ yeast extract and $15 \mathrm{~g} \cdot \mathrm{L}^{-1}$ agar (DSMZ, 2020)). The $\mathrm{pH}$ was adjusted to $\mathrm{pH} 6$ using $2 \mathrm{M} \mathrm{H}_{2} \mathrm{SO}_{4}$. These plates were incubated for $48 \mathrm{~h}$ at $30^{\circ} \mathrm{C}$ and kept for up to 30 days at $8^{\circ} \mathrm{C}$.

For seed culture fermentation, strains were obtained from agar plates and cultivated in liquid YM medium, $\mathrm{pH} 6$, at $30^{\circ} \mathrm{C}$ and $120 \mathrm{rpm}$ in a rotary shaker. After a maximum of $\sim 17 \mathrm{~h}, 1 \mathrm{~L}$ baffled shaking flasks containing $200 \mathrm{~mL}$ of YM medium were inoculated to an optical density $\left(\mathrm{OD}_{625}\right)$ of 0.1 a.u. and cultivated under the same conditions until the glucose concentration in the medium decreased to less than $1 \mathrm{~g} \cdot \mathrm{L}^{-1}$. This seed culture was used to inoculate CL production culture in further experiments.

\section{Fermentation Strategy for CL Production}

For CL fermentation, basic production culture medium (PCM), based on the composition of YNB (Y1251 Merck; Germany), consisting of mineral salts $\left(1.0 \mathrm{~g} \cdot \mathrm{L}^{-1} \mathrm{KH}_{2} \mathrm{PO}_{4}, 0.5 \mathrm{~g} \cdot \mathrm{L}^{-1}\right.$
$\left.\mathrm{MgSO}_{4}, 0.1 \mathrm{~g} \cdot \mathrm{L}^{-1} \mathrm{NaCl}, 0.1 \mathrm{~g} \cdot \mathrm{L}^{-1} \mathrm{CaCl}_{2}\right)$, compounds supplying trace elements $\left(500 \mu \mathrm{g} \cdot \mathrm{L}^{-1} \quad \mathrm{H}_{3} \mathrm{BO}_{3}, \quad 40 \mu \mathrm{g} \cdot \mathrm{L}^{-1} \quad \mathrm{CuSO}_{4}\right.$, $100 \mu \mathrm{g} \cdot \mathrm{L}^{-1} \mathrm{KI}, 200 \mu \mathrm{g} \cdot \mathrm{L}^{-1} \mathrm{FeCl}_{3}, 400 \mu \mathrm{g} \cdot \mathrm{L}^{-1} \mathrm{MnSO}_{4}$, $\left.200 \mu \mathrm{g} \cdot \mathrm{L}^{-1} \mathrm{Na}_{2} \mathrm{MoO}_{4}, 400 \mu \mathrm{g} \cdot \mathrm{L}^{-1} \mathrm{ZnSO}_{4}\right)$ and a vitamin solution $\left(2 \mu \mathrm{g} \cdot \mathrm{L}^{-1}\right.$ biotin, $400 \mu \mathrm{g} \cdot \mathrm{L}^{-1}$ calcium pantothenate, $2 \mu \mathrm{g} \cdot \mathrm{L}^{-1}$ folic acid, $2 \mathrm{mg} \cdot \mathrm{L}^{-1}$ inositol, $400 \mu \mathrm{g} \cdot \mathrm{L}^{-1}$ niacin, $200 \mu \mathrm{g} \cdot \mathrm{L}^{-1}$ p-aminobenzoic acid, $400 \mu \mathrm{g} \cdot \mathrm{L}^{-1}$ pyridoxine hydrochloride, $200 \mu \mathrm{g} \cdot \mathrm{L}^{-1}$ riboflavin, $400 \mu \mathrm{g} \cdot \mathrm{L}^{-1}$ thiamin hydrochloride), was used (Günther et al., 2010). Unless otherwise indicated, $0.6 \mathrm{~g} \cdot \mathrm{L}^{-1}$ urea and $50 \mathrm{~g} \cdot \mathrm{L}^{-1}$ glucose were added to the medium and inoculated to an $\mathrm{OD}_{625}$ of 0.3 a.u. from the previously prepared seed culture. All fermentations were conducted at $30^{\circ} \mathrm{C}$ and an initial $\mathrm{pH}$ of 2.5 for $10-$ 14 days, unless differently indicated (method optimized from Günther et al., 2010).

Fermentations in micro-bioreactor systems were performed in the BioLector I (m2p Labs GmbH; Germany) in 48-well Flowerplates $^{\circledR}$ (m2p-labs) with online monitoring of dissolved oxygen (DO) and backscatter (measured by backscattered light at $\lambda=620 \mathrm{~nm}$, gain 10) (Samorski et al., 2005; Funke et al., 2009). Data points were measured every $20 \mathrm{~min}$. For growth rate calculations, the moving averages of 50 data points of the backscatter signal were used to reduce noise. The wells were 
filled up to $1,300 \mu \mathrm{L}$ and shaken at $800 \mathrm{rpm}$. Cultivations were performed in duplicates or triplicates. Cell dry weight (CDW), $\mathrm{CL}$ concentration and concentration of remaining sugars were measured offline after termination of the fermentation.

Fermentations in shaking flasks were performed in $1 \mathrm{~L}$ baffled flasks with $200 \mathrm{~mL}$ medium at $120 \mathrm{rpm}$ in a rotary shaker. $1 \mathrm{~mL}$ samples were taken every $24 \mathrm{~h}$ for monitoring of $\mathrm{OD}, \mathrm{CDW}, \mathrm{CL}$ concentration as well as nitrogen and carbon source concentrations.

For bioreactor fermentations $700 \mathrm{~mL}$ of fermentation media were inoculated in 1 L INFORS HT Multifors bioreactors (Infors AG; Germany) with online monitoring of $\mathrm{DO}, \mathrm{pH}$, stirrer speed and $\mathrm{T}$. The reactors were aerated with $1 \mathrm{vvm}$ (volume of gas per volume of liquid per minute) of air and stirred within a range of $400-500 \mathrm{rpm}$, to maintain a DO value above $20 \%$. Two fermenters were started in parallel to ensure reproducibility of the fermentation. $1 \mathrm{~mL}$ samples were taken every $24 \mathrm{~h}$ for offline monitoring of OD, CDW, CL concentration as well as nitrogen and carbon source concentrations.

\section{Variation of Fermentation Parameters and Media Compositions}

The effect on growth and glycolipid formation of three different $\mathrm{pH}$ values $(2.5,4.0$, and 6.7$)$ was examined. This $\mathrm{pH}$ range was chosen for our screening, since acidic $\mathrm{pH}$ values were described to result in an increase in CL production rate with $U$. maydis (Günther et al., 2010). Furthermore the transfer phase of seed culture to the production culture medium was done during the early or late stationary phase, to assess a potential effect of substrate limitation of $S$. scitamineum on their CL productivity. Three different carbon sources were used for fermentation, at a concentration of $50 \mathrm{~g} \cdot \mathrm{L}^{-1}$ : sucrose, glucose and fructose. All three carbon sources can be metabolized by S. scitamineum (NBRC 32730) for glycolipid production (Morita et al., 2009a, 2015). $50 \mathrm{~g} \cdot \mathrm{L}^{-1}$ glucose $+0.6 \mathrm{~g} \cdot \mathrm{L}^{-1}$ urea [(IIa) $83.8 \mathrm{~mol}_{\mathrm{C}} \cdot \mathrm{mol}_{\mathrm{N}}{ }^{-1}$ ] was chosen based on Spoeckner and Günther as starting/basic $\mathrm{C} / \mathrm{N}$ ratio, showing the best results regarding $\mathrm{CL}$ concentrations with U. maydis (Spoeckner et al., 1999; Günther et al., 2010). We further examined the possible effect of halved [(I) 42.2 $\mathrm{mol}_{\mathrm{C}} \cdot \mathrm{mol}_{\mathrm{N}}{ }^{-1}$ ] and doubled [(III) $167.2 \mathrm{~mol}_{\mathrm{C}} \cdot \mathrm{mol}_{\mathrm{N}}{ }^{-1}$ ] $\mathrm{C} / \mathrm{N}$ ratios on $\mathrm{CL}$ formation and biomass growth. The $\mathrm{C} / \mathrm{N}$ ratio (II) was further applied at two concentration levels (IIa) and (IIb). The equivalent glucose and urea concentrations are summarized in Table 2 in the "Results" section.

To assess the effect of different media constituents on CL productivity and biomass growth, S. scitamineum was cultivated on the different fractions of PCM [mineral salts, vitamins (Vit), compounds supplying trace elements (TE)] separately, with or without an addition of $0.01 \mathrm{~g} \cdot \mathrm{L}^{-1} \mathrm{FeSO}_{4}$, corresponding to an increase by $\sim 54 \mathrm{~mol}$ in iron ions. All used media combinations are summarized in Table 2.

\section{Analytical Methods}

For biomass quantification, the optical density was measured photometrically at $625 \mathrm{~nm}$ (GENESYS $^{\mathrm{TM}} 10 \mathrm{UV}$, Thermo Fisher Scientific; United States). For all further analyses, $1 \mathrm{~mL}$ sample was centrifuged at $16,060 \mathrm{~g}$ for $10 \mathrm{~min}$ at RT. The supernatant was used for urea and sugar analysis. Urea concentration was determined photometrically, via enzymatic reaction with a urea/ammonia test kit (R-Biopharm; Germany). Sugar concentration was measured via HPLC with a Supelcogel $8 \mathrm{H}$ 59246-U column (Merck; Germany), at $30^{\circ} \mathrm{C}$ with $5 \mathrm{mM}$ $\mathrm{H}_{2} \mathrm{SO}_{4}$ as mobile phase, with a flow rate of $0.6 \mathrm{~mL} \cdot \mathrm{min}^{-1}$ and a running time of $15 \mathrm{~min}$. Sucrose, glucose, fructose and erythritol were detected via a refractive index detector (RI 8120, Bischoff GmbH; Germany).

The pellet was washed with acidic water $\left(\mathrm{pH} 2 ; \mathrm{H}_{2} \mathrm{SO}_{4}\right)$ to remove residual sugars, then $1 \mathrm{~mL}$ of ethanol was added to the pellet for CL extraction. The extraction with $1 \mathrm{~mL}$ ethanol was repeated and both extracts were unified and stored at $-18^{\circ} \mathrm{C}$ until further analysis (Günther, 2014). The remaining pellet after ethanol extraction was dried and used for gravimetric CDW determination.

For CL quantification, the ethanol extracts were applied to HPTLC Silica gel $60 \mathrm{~F}_{254}$ plates (Merck; Germany) in a chloroform-methanol-water (65:25:4) system. The spots were visualized by dipping into a developing solution (mixture of acetic acid, sulfuric acid and anisaldehyde) and heating until color intensity stabilized. The spots intensities were then quantified with the software Image-J and the CL concentrations calculated based on the internal calibration with CL standards.

For obtaining the standards, CL was extracted with ethanol, as previously described, from the pellet of $25 \mathrm{~mL} \mathrm{~S}$. scitamineum culture broth. The extract was evaporated at $45^{\circ} \mathrm{C}$ and the obtained white/yellowish CL was grinded to a powder. This CL fraction was suspended twice in $4 \mathrm{~mL}$ of ethyl acetate per g CL and incubated for $30 \mathrm{~min}$ at RT to remove remaining fatty acids and MEL (Günther, 2014). The suspension was then centrifuged for $10 \mathrm{~min}$ at $16,060 \mathrm{~g}$ and $4^{\circ} \mathrm{C}$ and the pellet containing the purified $\mathrm{CL}$ was dried at $45^{\circ} \mathrm{C}$ and grinded to a powder. The purity of the standard was determined densitometrically via HPTLC as $91.6 \pm 2.9 \%(n=4)$. This purified CL was dissolved in ethanol, at concentrations of $10,5,2.5$, and $1.25 \mathrm{~g} \cdot \mathrm{L}^{-1}$ and used as standard for internal calibration. Values from different plates are referred to the mean of sample PCM (IIa) for proper comparison.

For structural analysis a matrix consisting of $200 \mathrm{~g} \cdot \mathrm{L}^{-1}$ dihydroxybenzoic acid, $1.15 \mathrm{~g} \cdot \mathrm{L}^{-1}$ ammonium hydrogen phosphate, $0.1 \mathrm{~g} / \mathrm{L}$ Octyl- $\beta$-D-glycopyranoside, $0.1 \% \quad(\mathrm{v} / \mathrm{v})$ trifluoroacetic acid in $90 \%$ acetonitrile and $10 \% \mathrm{ddH}_{2} \mathrm{O}$ was applied to the HPTLC plates. Polypropylene glycol was spotted on the plate as internal standard to verify the mass calibration of the MS system. The plates were then dried overnight in a desiccator, prior to sample application for the MALDI-TOF-MS measurement. Then they were developed analogous to the method for CL quantification and separated due to polarity, however without treatment with the developing solution. Bands were scanned over their complete running distance with Bruker Ultraflex II TOF/TOF controlled by flex Control software (Bruker Daltonics; United States). Spectra were calculated in the range of 200-2,000 Da $\left(\mathrm{m} \cdot \mathrm{z}^{-1}\right)$ based on the mean value of five spots at a distance of $0.6 \mathrm{~mm}$ in the running direction, with 200 laser shots for each. The obtained data was analyzed with flex Analysis and TLC MALDI software (Bruker Daltonics; United States), and 
TABLE 1 | Homologous genes of CL biosynthesis gene cluster in S. scitamineum. Amino acid (AA) sequence similarity was calculated via the EMBOSS Needle software (Madeira et al., 2019).

\begin{tabular}{|c|c|c|c|c|c|c|c|c|}
\hline $\begin{array}{l}\text { U. maydis } \\
521\end{array}$ & Description & $\begin{array}{c}\text { Accession } \\
\text { No }\end{array}$ & $\begin{array}{c}\text { Gene } \\
\text { sequence } \\
\text { length (bp) }\end{array}$ & $\begin{array}{l}\text { Homolog in } \\
\text { S. scitamineum } \\
\text { (Accesion-No) }\end{array}$ & Description & $\begin{array}{c}\text { Gene } \\
\text { sequence } \\
\text { length (bp) }\end{array}$ & $\begin{array}{l}\text { Similarity } \\
\text { (AA) }\end{array}$ & $\begin{array}{l}\text { Identity } \\
\text { (AA) }\end{array}$ \\
\hline cyp1 & $\begin{array}{l}\text { Cytochrome P450 enzyme } \\
\text { invovled in glycolipid } \\
\text { production }\end{array}$ & XP_011392749 & 1923 (rev) & CDU25005.1 & $\begin{array}{l}\text { Related to } \\
\text { cytochrome } \\
\text { P450 }\end{array}$ & 1794 (rev) & $83 \%$ & $77 \%$ \\
\hline cyp2 & $\begin{array}{l}\text { Cytochrome P450 } \\
\text { monooxygenase involved in } \\
\text { ustilagic acid production }\end{array}$ & XP_011392727 & $1608(\mathrm{rev})$ & CDS01512.1 & $\begin{array}{l}\text { Hypothetical } \\
\text { protein }\end{array}$ & 1602 (rev) & $89 \%$ & $83 \%$ \\
\hline ugt1 & $\begin{array}{l}\text { Ustilagic acid glycosyl } \\
\text { transferase }\end{array}$ & XP_011392734 & 1737 (rev) & CDU25009.1 & um12340 & 1734 (rev) & $80 \%$ & $69 \%$ \\
\hline uat1 & $\begin{array}{l}\text { Ustilagic acid } \\
\text { acyltransferase }\end{array}$ & XP_011392730 & 1542 (rev) & CDU25004.1 & $\begin{array}{c}\text { Probable } \\
\text { ustilagic acid } \\
\text { acyltransferase }\end{array}$ & 1536 (rev) & $80 \%$ & $69 \%$ \\
\hline fas2 & Fatty acid synthase FAS2 & XP_011392728 & 11115 (rev) & CDU25002.1 & $\begin{array}{l}\text { Probable fatty } \\
\text { acid synthase, } \\
\text { beta and alpha } \\
\text { chains }\end{array}$ & 11121 (rev) & $85 \%$ & $74 \%$ \\
\hline und1 & Ustilagic acid hydroxylase & XP_011392733 & 903 (for) & CDU25008.1 & $\begin{array}{l}\text { Probable } \\
\text { ustilagic acid } \\
\text { hydroxylase }\end{array}$ & 915 (for) & $77 \%$ & $63 \%$ \\
\hline ahd1 & Alpha-hydroxylase AHD1 & XP_011392763.1 & 1151 (for) & CDU25010.1 & $\begin{array}{l}\text { Probale aplha- } \\
\text { hydroxylase } \\
\text { AHD1 }\end{array}$ & 1140 (for) & $88 \%$ & $77 \%$ \\
\hline rua1 & $\begin{array}{l}\text { Ustilagic acid biosynthesis } \\
\text { regulator rua1 }\end{array}$ & XP_011392726 & 2274 (for) & CDU25000.1 & $\begin{array}{l}\text { Related to } \\
\text { regulator of } \\
\text { ustilagic acid } \\
\text { biosynthesis }\end{array}$ & 2052 (for) & $51 \%$ & $39 \%$ \\
\hline atr1 & $\mathrm{ABC}$ transporter & XP_011392729 & 4149 (for) & CDU25003.1 & $\begin{array}{l}\text { Probable ABC } \\
\text { transporter }\end{array}$ & 4203 (for) & $82 \%$ & $73 \%$ \\
\hline orf1 & Unknown & XP_011392732 & 1149 (for) & CDU25007.1 & $\begin{array}{l}\text { Uncharacterized } \\
\text { protein }\end{array}$ & 1164 (rev) & $80 \%$ & $64 \%$ \\
\hline uat2 & $\begin{array}{l}\text { Ustilagic acid } \\
\text { acyltransferase }\end{array}$ & XP_011392731 & 1290 (for) & CDU25006.1 & $\begin{array}{l}\text { Uncharacterized } \\
\text { protein }\end{array}$ & 1302 (rev) & $63 \%$ & $49 \%$ \\
\hline orf2 & Unknown & XP_011392750 & 348 (rev) & $\begin{array}{l}\text { No significant } \\
\text { similarity found }\end{array}$ & & & & \\
\hline
\end{tabular}

Rev, reverse orientation; for, forward orientation.

the detected masses of the $[\mathrm{M}+\mathrm{Na}]^{+}$adducts were compared with known CL and MEL molecular masses from $U$. maydis (Spoeckner et al., 1999; Teichmann et al., 2011a; Beck et al., 2019). In combination with the polarity pattern, probable CL structures were derived from the mass spectrum of each spot. Only masses with an intensity above 500 a.u. (threshold) were considered. The $\mathrm{m} / \mathrm{z}$ resolution was $1 \mathrm{Da}$. Therefore, a constant pattern of the isotopic distribution could be obtained for each spot and was considered for data analysis. Each detected mass spot consists of three peaks, with a mass difference of $1 \mathrm{Da}$ and diminishing relative abundance, explained by the natural isotopic distribution. This TLC coupled MALDI-TOF-MS method was first described for CL analysis by Günther and recently published in detail by Günther (2014) and Beck et al. (2019).

\section{RESULTS AND DISCUSSION}

Examinations with different media compositions and $\mathrm{pH}$ values were conducted in the micro-bioreactor system. Observations on CL formation kinetics were either based on shaking flask or bioreactor experiments.

\section{Comparative Genome Analysis of the CL Gene Cluster in $U$. maydis and} S. scitamineum

The CL gene cluster is highly preserved amongst the known and sequenced CL producers U. maydis and A. flocculosa. Although A. flocculosa shares only an average gene sequence identity of about $50 \%$ with $U$. maydis, their CL-clusters share high sequence identities (up to 97\%). Only the homolog for Rual shares a low identity of 23\% (Teichmann et al., 2007, 2011a; Morita et al., 2013; Dutheil et al., 2016). Cyp 1, a gene encoding a P450 oxidoreductase, which is essential for CL synthesis, is also confirmed to be present in other strains that produce CL, such as M. aphidis and P. hubeiensis pro tem (Morita et al., 2013).

In the clade S. scitamineum, which is known to produce both MEL and CL, a homolog to the sequenced MEL biosynthesis gene cluster was identified recently (Deinzer, 2017). Furthermore, CL 


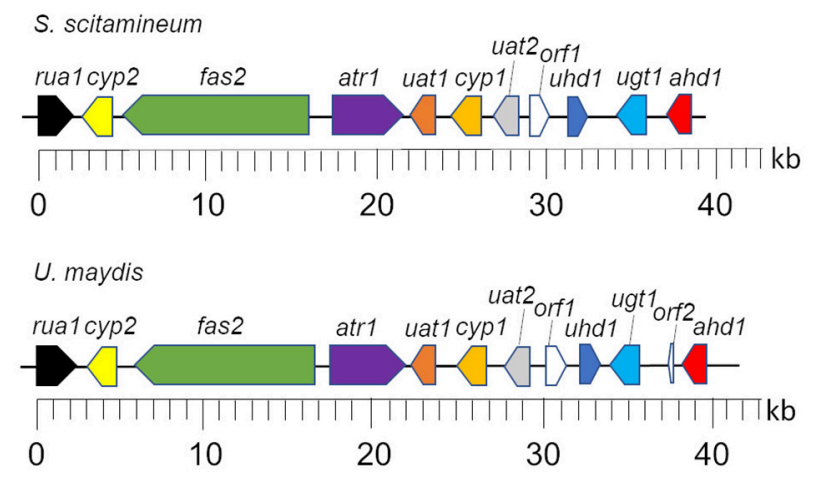

FIGURE 2 | Genetic organization of the CL biosynthesis cluster of S. scitamineum and U. maydis. Gene designations are described in Table 1. Figure was modified after Teichmann et al. (2011a).

structures obtained from U. maydis and S. scitamineum share a high structural identity. Therefore it was of a high probability to find a homologous CL gene cluster in S. scitamineum as well. Via sequence homology analysis, we scanned the public available genome of S. scitamineum (Dutheil et al., 2016) and were able to identify 11 out of 12 clustered homologs to the genes associated with CL biosynthesis in U. maydis (Table 1). All 11 genes are located on scaffold 33 (NCBI accession number LK056681) with a spanning region of $\sim 40 \mathrm{~kb}$ in identical genetic organization as in U. maydis (Figure 2) and with high similarities varying between 63 and $89 \%$ to the $U$. maydis homologs, except for Rual, that shares only $51 \%$ similarity.

However, the potential homolog to Rual that we identified in S. scitamineum, annotated as CDU25000.1, contains a Cys2His2-motif at the N-terminus that has $92.9 \%$ similarity (Supplementary Figure 1). This corresponds to the homology results observed on $U$. maydis and A. flocculosa, where only the Cys2His2-motif within Rual had a high identity in both microorganisms (Teichmann et al., 2011a).

These results confirmed the expected conservation of the CL biosynthesis pathway in S. scitamineum and pave the way for further molecular biological experiments to study gene function and perform strain optimization.

\section{Observations on the Growth Behavior of S. scitamineum in Complex Medium}

In order to cover all nutrients necessary for biomass growth and determine growth kinetics of $S$. scitamineum, seed cultures were grown on the complex YM medium. A maximum growth rate of $\mu_{\max }=0.15 \pm 0.02 \mathrm{~h}^{-1}$ was observed within the first $8 \mathrm{~h}$ of cultivation at $30^{\circ} \mathrm{C}, \mathrm{pH} 6$ and $800 \mathrm{rpm}$ in the micro-bioreactor system, while maximum backscatter was reached after $\sim 30 \mathrm{~h}$ (Figure 3). However, no CL formation was observed under these conditions in the seed culture (Figure 1C).

When U. maydis (DSM 17146) was cultivated with resting cells, i.e., without further growth in the production culture, the biomass transfer point from seed culture to the CL fermentation culture showed an effect on the subsequent CL productivity

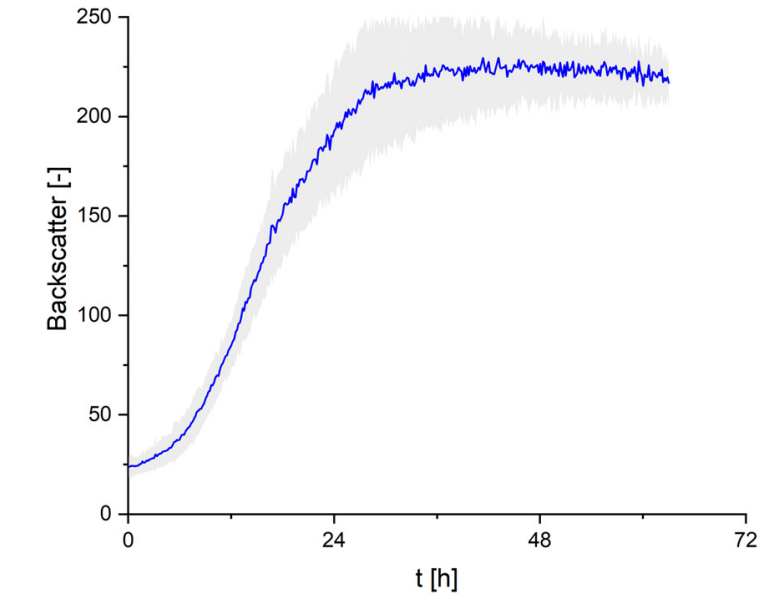

FIGURE 3 | Growth kinetics of S. scitamineum seed culture in complex YM medium, cultivated in the micro-bioreactor system at an inoculation $\mathrm{pH}$ of 6.0 . Error bars are deviated from 8 parallel cultivations $(n=8)$.

(Günther et al., 2010). In order to exclude a similar sensitivity with S. scitamineum, cell biomass was transferred either at the early $(\sim 28 \mathrm{~h})$ or late stationary phase $(\sim 42 \mathrm{~h})$ from the seed culture to the CL production culture. No significant effect of the biomass transfer phase was observed, neither on the obtained CDW nor on subsequent CL formation, indicating a tolerance of S. scitamineum toward substrate limiting conditions (results not shown here). All cultivations for CL production were therefore inoculated from this seed culture during the early stationary phase, at $\sim 28 \mathrm{~h}$.

\section{Effect of pH Value}

Fungal secondary metabolism in general is regulated by various environmental stimuli, including $\mathrm{pH}$ (Brakhage, 2013). In order to examine a $\mathrm{pH}$ dependency of CL synthesis with $\mathrm{S}$. scitamineum, three different $\mathrm{pH}$ ranges were used for fermentation in PCM: $\mathrm{pH}$ 6.7, the $\mathrm{pH}$ level of the used defined PCM without any adjustment, an acidic $\mathrm{pH}$ of 2.5 and $\mathrm{pH} 4.0$. At $\mathrm{pH} 6.7$ the worst growth behavior amongst the examined $\mathrm{pH}$ ranges was observed (Figure 4A). A biomass concentration as low as $4.3 \pm 0.2 \mathrm{~g} \cdot \mathrm{L}^{-1}$ was obtained, while no CL was detected (Table 2). At pH 4 backscatter and growth rate (Figures 4A,B) were slightly higher over the course of fermentation, with a $\mathrm{C}_{\mathrm{CDW}}$ of $5.1 \pm 0.4 \mathrm{~g} \cdot \mathrm{L}^{-1}$. However, no CL was produced here either, compared to $\mathrm{pH} 2.5$ where we obtained a $c_{\mathrm{CDW}}$ of $4.6 \pm 0.3 \mathrm{~g} \cdot \mathrm{L}^{-1}$ and a $\mathrm{c}_{\mathrm{CL}}$ of $5.1 \pm 0.3 \mathrm{~g} \cdot \mathrm{L}^{-1}$.

While at $\mathrm{pH} 2.5$ the lag phase was longest and the maximum growth rate $\mu_{\max }$ was lowest, an increase in optical density was observed up to $216 \mathrm{~h}$ of fermentation, showing a stable growth over a longer time span. This was also reflected in the DO level (Figure 4C), where it decreased to lower than 25\% after an initial lag phase. At $\mathrm{pH} 4$ and $\mathrm{pH} 6.7$ growth rates were high only in the first $96 \mathrm{~h}$, indicating slightly better growth conditions in the beginning. This is when the provided urea is assumed to still be present in the medium, thus enabling 
TABLE 2 | Used pH values and media compositions for the screening experiment with S. scitamineum and obtained CL and CDW concentrations, CL yield and glucose and erythritol concentrations in the medium at the end of fermentation.

\begin{tabular}{|c|c|c|c|c|c|c|c|c|}
\hline $\begin{array}{l}\text { Medium } \\
\text { composition }\end{array}$ & $\begin{array}{c}c_{C-\text { source }} \\
{\left[g \cdot L^{-1}\right]}\end{array}$ & $\begin{array}{c}\text { CUrea } \\
{\left[g \cdot L^{-1}\right]}\end{array}$ & $\begin{array}{c}\text { Inoculum } \\
\text { pH }\end{array}$ & $\begin{array}{c}\mathrm{C}_{\mathrm{CL}}(\mathrm{t}=240 \mathrm{~h}) \\
{\left[\mathrm{g} \cdot \mathrm{L}^{-1}\right]}\end{array}$ & $\begin{array}{c}Y_{P / S}(t=240 h) \\
{\left[g \cdot g^{-1}\right]}\end{array}$ & $\begin{array}{c}C_{C D W}(t=240 h) \\
{\left[g \cdot L^{-1}\right]}\end{array}$ & $\begin{array}{c}\text { CGlucose }(t=240 \mathrm{~h}) \\
{\left[\mathrm{g} \cdot \mathrm{L}^{-1}\right]}\end{array}$ & $\begin{array}{c}\text { Crythritol } \\
(t=240 \mathrm{~h})\left[\mathrm{g} \cdot \mathrm{L}^{-1}\right]\end{array}$ \\
\hline PCM & Glucose: 50 & 0.6 & 6.7 & $0.0 \pm 0.0$ & 0.00 & $4.3 \pm 0.2$ & $1.8 \pm 0.0$ & $14.3 \pm 0.5$ \\
\hline PCM & Glucose: 50 & 0.6 & 4 & $0.0 \pm 0.0$ & 0.00 & $5.1 \pm 0.4$ & $1.4 \pm 0.0$ & $4.2 \pm 0.4$ \\
\hline PCM (Ila) & Glucose: 50 & 0.6 & 2.5 & $5.1 \pm 0.3$ & 0.10 & $4.6 \pm 0.3$ & $0.4 \pm 0.0$ & $4.7 \pm 0.3$ \\
\hline PCM (III) & Glucose: 100 & 0.6 & 2.5 & $4.8 \pm 1.2$ & 0.05 & $5.6 \pm 0.2$ & $24.2 \pm 0.5$ & $20.2 \pm 0.4$ \\
\hline PCM (Illb) & Glucose: 100 & 1.2 & 2.5 & $2.1 \pm 0.2$ & 0.02 & $7.5 \pm 0.3$ & $1.9 \pm 0.0$ & $21.6 \pm 0.9$ \\
\hline PCM (I) & Glucose: 50 & 1.2 & 2.5 & $<0.5$ & $<0.01$ & $5.4 \pm 0.0$ & $1.1 \pm 0.1$ & $0.9 \pm 0.3$ \\
\hline PCM & Fructose: 50 & 0.6 & 2.5 & $6.1 \pm 0.1$ & 0.12 & $4.4 \pm 0.1$ & $0.0 \pm 0.0$ & $0.3 \pm 0.0$ \\
\hline PCM & Sucrose: 50 & 0.6 & 2.5 & $6.6 \pm 0.2$ & 0.13 & $4.3 \pm 0.3$ & $0.4 \pm 0.0$ & $3.1 \pm 0.3$ \\
\hline $\mathrm{PCM}+\mathrm{FeSO}_{4}$ & Glucose: 50 & 0.6 & 2.5 & $1.4 \pm 0.1$ & 0.03 & $4.6 \pm 0.2$ & $1.4 \pm 0.1$ & $6.7 \pm 0.5$ \\
\hline $\begin{array}{l}\text { PCM without trace } \\
\text { element solution } \\
\text { (PCM-TE) }\end{array}$ & Glucose: 50 & 0.6 & 2.5 & $0.0 \pm 0.0$ & 0.00 & $2.3 \pm 0.5$ & $25.0 \pm 0.5$ & $4.2 \pm 0.4$ \\
\hline $\begin{array}{l}\text { PCM without trace } \\
\text { element } \\
\text { solution }+\mathrm{FeSO}_{4} \\
\left(\mathrm{PCM}-\mathrm{TE}+\mathrm{FeSO}_{4}\right)\end{array}$ & Glucose: 50 & 0.6 & 2.5 & $0.0 \pm 0.0$ & 0.00 & $3.5 \pm 0.2$ & $20.0 \pm 0.3$ & $3.2 \pm 0.2$ \\
\hline $\begin{array}{l}\text { PCM without vitamin } \\
\text { solution (PCM-Vit) }\end{array}$ & Glucose: 50 & 0.6 & 2.5 & $3.8 \pm 0.6$ & 0.08 & $4.4 \pm 0.3$ & $0.4 \pm 0.0$ & $4.8 \pm 0.2$ \\
\hline $\begin{array}{l}\text { PCM without vitamin } \\
\text { solution }+\mathrm{FeSO}_{4} \\
\left(\mathrm{PCM}-\mathrm{Vit}+\mathrm{FeSO}_{4}\right)\end{array}$ & Glucose: 50 & 0.6 & 2.5 & $1.5 \pm 0.1$ & 0.03 & $4.5 \pm 0.4$ & $1.6 \pm 0.3$ & $6.4 \pm 0.5$ \\
\hline
\end{tabular}
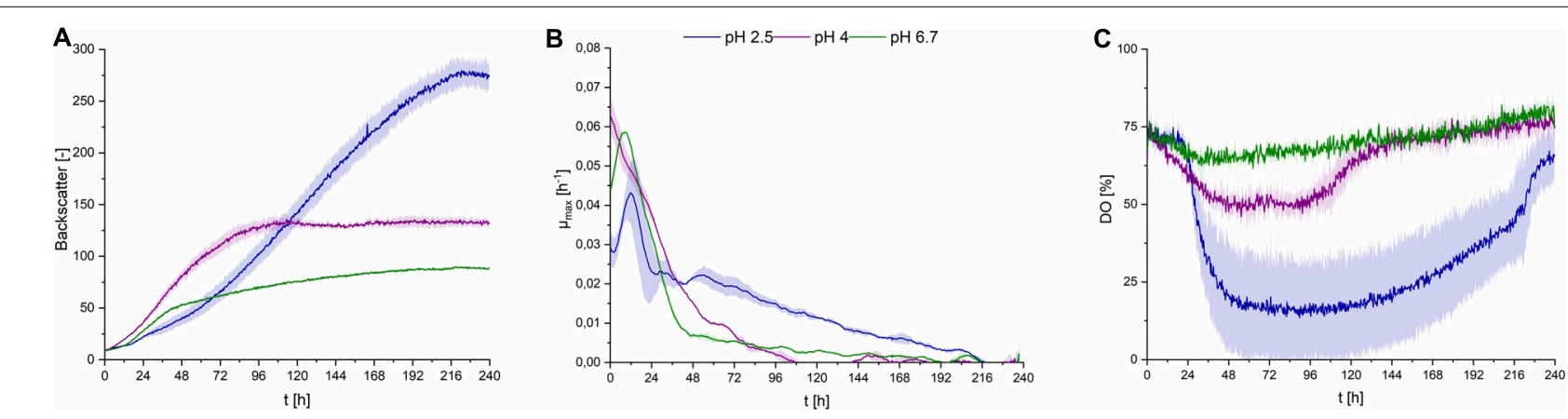

FIGURE 4 | Observations on S. scitamineum during fermentation in the micro-bioreactor system, using PCM, $50 \mathrm{~g} \cdot \mathrm{L}^{-1} \mathrm{glucose}$ and $0.6 \mathrm{~g} \cdot \mathrm{L}^{-1}$ urea at an inoculation $\mathrm{pH}$ of 2.5, 4, or 6.7. (A) Backscatter light signal, (B) specific growth rates, and (C) DO level. Error bars are deviated from biological triplicates $(n=3)$.

unlimited exponential growth. These higher growth rates are also reflected in the DO levels at $\mathrm{pH} 4$ and 6.7, where the DO decreases during the first $96 \mathrm{~h}$, then increases to its initial level. After this first growth phase, the growth rates at $\mathrm{pH} 4$ and 6.7 decreased rapidly and overall biomass formation was lower at $\mathrm{pH}$ 6.7, compared to $\mathrm{pH} 2.5$, despite the availability of carbon source. These observations on the growth behavior are further discussed in section "Effect of C/N Ratio" and "CL Formation Kinetics in Shaking Flasks and $1 \mathrm{~L}$ Bioreactors," in relation to the urea level in the fermentation medium.

When interpreting growth behavior, it is important to consider both backscatter and DO levels, because the backscatter signal, which is used as indicator for biomass concentration, can also be affected by CL crystals in the medium. However at $\mathrm{pH} 4$ and 6.7, where no CL production occurred, the backscatter signal is assumed to result only from biomass in the media, while at $\mathrm{pH}$
2.5, this signal may also be affected by CL concentration. This is shown in the higher CDW values at the end of fermentation at $\mathrm{pH}$ 4 , compared to $\mathrm{pH} 2.5$, although backscatter values were lower.

The obtained results show that the optimal $\mathrm{pH}$ value amongst the examined range for $\mathrm{CL}$ synthesis is at $\mathrm{pH} 2.5$, which coincides with similar observations on other CL producing microorganisms. A pH range of 3-3.5 is reported to result in a threefold increase of product formation rate of CL by $U$. maydis compared to a pH range of 5-6 (Günther et al., 2010). This could partly be due to a decrease in product inhibition in this $\mathrm{pH}$ range. $\mathrm{CL}$ are known to precipitate in acidic $\mathrm{pH}$ ranges (Figure 1B), thus resulting in a decrease in CL concentration in the liquid medium (Haskins, 1950). Another cause for the observed results is likely to be due to stimulation of the secondary metabolism, caused by stress induced by the acidic $\mathrm{pH}$ range. However these results may vary, depending on the used fermentation media. 
The synthesis of CL observed by Geiser et al. (2014), on various Ustilaginaceae species for instance, occurred at $\mathrm{pH}$ 6.5. Therefore it can be assumed, that the $\mathrm{pH}$ dependency of CL formation is not only related to metabolic factors and stressors, but also to interactions between the produced CL and components present in the fermentation medium.

Considering the large impact of $\mathrm{pH}$ observed in this study, it would be interesting to further examine the effect of smaller variations in $\mathrm{pH}$ value (around $\mathrm{pH} 2.5$ ) on $\mathrm{CL}$ productivity. Especially in regards to a potential CL fermentation in an industrial scale, more knowledge on $\mathrm{pH}$ sensitivity is crucial for process control. However, this observed highly acidic $\mathrm{pH}$ optimum is of great advantage regarding sterility aspects. At such low $\mathrm{pH}$ values, the maintenance of a sterile process is much easier compared to higher $\mathrm{pH}$ ranges, where contamination of the fermenter is more likely to happen.

\section{Effect of C/N Ratio}

With the adjusted $\mathrm{pH}$ range of 2.5 , three different $\mathrm{C} / \mathrm{N}$ ratios were used in the fermentation medium, at different concentration levels. Both cultures with $1.2 \mathrm{~g} \cdot \mathrm{L}^{-1}$ urea [(I) $42.2 \mathrm{~mol}_{\mathrm{C}} \cdot \mathrm{mol}_{\mathrm{N}}{ }^{-1}$ and (IIb) $83.8 \mathrm{~mol}_{\mathrm{C}} \cdot \mathrm{mol}_{\mathrm{N}}{ }^{-}$1] showed higher maximum growth rates, while in cultures containing only $0.6 \mathrm{~g} \cdot \mathrm{L}^{-1}$ urea [(IIa) 83.8 $\mathrm{mol}_{\mathrm{C}} \cdot \mathrm{mol}_{\mathrm{N}}{ }^{-1}$ and (III) $167.2 \mathrm{~mol}_{\mathrm{C}} \cdot \mathrm{mol}_{\mathrm{N}}{ }^{-1}$ ] growth kinetics were slower in the first $24 \mathrm{~h}$, indicating a direct relation of urea content in the fermentation medium to growth kinetics (Figures 5A,B). This was also reflected in the rapid decrease in DO level in the first 24-48 h (Figure 5C), compared to cultures with lower Urea concentrations, correlating to the shorter lag phase also observed in backscatter values.

This may be an indication, to two metabolic phases for S. scitamineum, the first occurring under nitrogen availability where growth is exponential and the second under nitrogen limited conditions, where a linear secondary growth phase occurs, as observed for U. maydis (Klement et al., 2012; Voll et al., 2012; Hartmann et al., 2018). Under nitrogen availability, the cells can metabolize glucose faster and thus show higher growth rates. This can be observed in the growth rates, where the highest growth rates remain over a longer time span for media containing $1.2 \mathrm{~g} \cdot \mathrm{L}^{-1}$ urea, compared to those with only $0.6 \mathrm{~g} \cdot \mathrm{L}^{-1}$. When nitrogen is depleted, cells shift to their secondary growth phase, where morphological changes and an increase in $\mathrm{C} / \mathrm{N}$ ratio of the biomass probably occur, as previously observed for U. maydis (Klement et al., 2012; Voll et al., 2012). This increase in $\mathrm{C} / \mathrm{N}$ ratio may be attributed to triglyceride accumulation in the cells, resulting in the morphological changes (Ageitos et al., 2011; Klement et al., 2012). A further cause for the increase in backscatter signal occurring in this secondary growth phase can be attributed to the utilization of internal nitrogen storage by the cells, while overall metabolism levels are lower, thus explaining the decreased oxygen uptake in the second growth phase, reflected in the increase in DO level. An increase in cell number, corresponding to the increase in CDW was observed for $U$. maydis even after nitrogen depletion, while the carbon source was still present in the media (Klement et al., 2012). In order to get more insight on these observations, nitrogen levels in the medium needed to be studied more intensively, which was performed in the bioreactor. Due to larger initial volumes, sampling was possible and the urea concentration in the medium was measured (section "CL Formation Kinetics in Shaking Flasks and 1 L Bioreactors").

In regards to overall concentrations, higher biomass concentrations were obtained from media containing $1.2 \mathrm{~g} \cdot \mathrm{L}^{-1}$ urea, compared to the respective glucose concentrations with only $0.6 \mathrm{~g} \cdot \mathrm{L}^{-1}$ urea (Table 2 ). This may seem to contradict the lower end-backscatter values observed for media containing $1.2 \mathrm{~g} \cdot \mathrm{L}^{-1}$ urea, however, in that case the higher backscatter values observed for media containing only $0.6 \mathrm{~g} \cdot \mathrm{L}^{-1}$ urea are probably caused by an accumulated backscatter signal induced from both biomass and CL crystals.

At the lowest $\mathrm{C} / \mathrm{N}$ ratio less than $0.5 \mathrm{~g} \cdot \mathrm{L}^{-1} \mathrm{CL}$ was produced, while at the higher $\mathrm{C} / \mathrm{N}$ ratio and the same amount of urea this amount increased to $2.1 \pm 0.2 \mathrm{~g} \cdot \mathrm{L}^{-1}$. With the low level of $0.6 \mathrm{~g} \cdot \mathrm{L}^{-1}$ urea, maximum $\mathrm{CL}$ concentrations were obtained for both $\mathrm{C} / \mathrm{N}$ ratios, with a $\mathrm{c}_{\mathrm{CL}}$ of $5.1 \pm 0.3 \mathrm{~g} \cdot \mathrm{L}^{-1}$ at $83.8 \mathrm{~mol}_{\mathrm{C}} \cdot \mathrm{mol}_{\mathrm{N}}{ }^{-1}$ and $4.8 \pm 1.2 \mathrm{~g} \cdot \mathrm{L}^{-1}$ at $167.2 \mathrm{~mol}_{\mathrm{C}} \cdot \mathrm{mol}_{\mathrm{N}}{ }^{-1}$ (Table 2). As a result, low overall nitrogen concentrations together with a high $\mathrm{C} / \mathrm{N}$ ratio seem to favor $\mathrm{CL}$ synthesis and were selected for further experiments in the bioreactor. At higher nitrogen concentrations, a larger amount of the available carbon source is used for biomass formation, before limitation occurs and the cells start producing CL. Therefore, for batch fermentation, high $\mathrm{C} / \mathrm{N}$ ratios with low nitrogen concentrations are favored. However, if a fed batch process is designed, lower $\mathrm{C} / \mathrm{N}$ ratios with feeding of carbon source may be considered. This would increase the available biocatalysators, thus enabling higher CL titers after feeding.

Furthermore, in media containing $100 \mathrm{~g} \cdot \mathrm{L}^{-1}$ glucose an increase in synthesized erythritol was observed, with concentrations up to $20 \mathrm{~g} \cdot \mathrm{L}^{-1}$. In media containing only $50 \mathrm{~g} \cdot \mathrm{L}^{-1}$ glucose, a maximum of $5 \mathrm{~g} \cdot \mathrm{L}^{-1}$ erythritol was measured. Erythritol is a known secondary metabolite produced by $S$. scitamineum and intermediate for the MEL synthesis (Peros et al., 1986). If erythritol production is not targeted, this effect of increased erythritol productivity at high initial glucose concentrations should therefore also be considered, when designing a fermentation process.

\section{Effect of Carbon Source}

While nitrogen concentration revealed to be of importance for biomass formation and the induction of CL synthesis, the used carbon source may be of relevance for the produced CL titer. S. scitamineum is known to metabolize glucose, fructose and sucrose at similar rates (Peros et al., 1986), and S. scitamineum (NBRC 32730) produced MEL using all three carbohydrates (Morita et al., 2009a,b).

Using all three substrates at a concentration of $50 \mathrm{~g} \cdot \mathrm{L}^{-1}$ in PCM, CL production was observed. Cells growing on sucrose showed higher growth rates, compared to glucose or fructose (Figures 6A,B). DO level barely decreased when fructose was the carbon source, compared to glucose and sucrose, where a decrease to up to less than $25 \%$ occurred (Figure 6C). This may be explained by the overall lower uptake rates of fructose, compared to glucose, when both sugars are present in the fermentation 

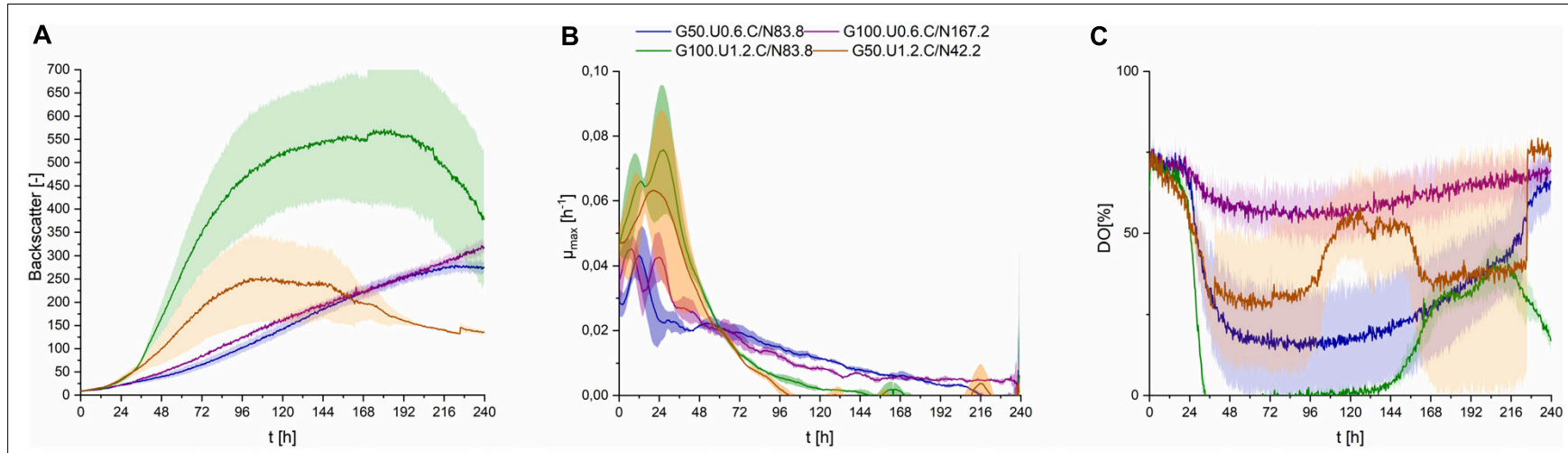

FIGURE 5 | Observations on S. scitamineum during fermentation in the micro-bioreactor system, using PCM at an inoculation pH of 2.5, while glucose and urea concentrations were varied. Glucose concentration in the medium in $\mathrm{g} \cdot \mathrm{L}^{-1}$ is indicated as $\mathrm{G}$, urea concentration in $\mathrm{g} \cdot \mathrm{L}^{-1}$ is indicated as $\mathrm{U}$, while $\mathrm{C} / \mathrm{N}$ ratio in $\mathrm{mol} \cdot \mathrm{mol}^{-1}$ is indicated as C/N. (A) Backscatter light signal, (B) specific growth rates, and (C) DO level. Error bars are deviated from biological duplicates or triplicates $(n \geq 2)$.

medium (Morita et al., 2015). This difference in oxygen uptake of S. scitamineum depending on the carbon source glucose or fructose, may further explain the unsteady DO levels when using sucrose as substrate, in which both sugars can be metabolized after hydrolysis of sucrose to both its constituents, glucose and fructose. However, in order to get a better understanding on the different growth behaviors depending on the carbon source, further studies analysing the carbohydrate concentrations in the medium and uptake rates during each fermentation phase need to be done. Nonetheless, all three carbon sources yielded similar amounts of biomass overall (Table 2), which corresponds to previous observations (Peros et al., 1986). The higher backscatter levels with sucrose may be explained by the comparably higher CL contents in these fermentations, which may interfere with scattered light measurement.

CL concentrations were slightly higher with sucrose, compared to glucose, resulting in a $c_{C L}$,sucrose of $6.6 \pm 0.2 \mathrm{~g} \cdot \mathrm{L}^{-1}$, $\mathrm{c}_{\mathrm{CL}, \text { glucose }}$ of $5.1 \pm 0.3 \mathrm{~g} \cdot \mathrm{L}^{-1}$ and $\mathrm{c}_{\mathrm{CL}}$,fructose of $6.1 \pm 0.1 \mathrm{~g} \cdot \mathrm{L}^{-1}$, respectively (Table 2).

Similar results were found in this context by Günther et al. They observed an increase in CL concentrations with $U$. maydis when using sucrose as $C$ source (Günther et al., 2010). Therefore, sucrose was selected as the most favorable carbon source for CL production and should be used in future experiments.

\section{Effect of Media Constituents}

The screening media reported for S. scitamineum cultivation for CL synthesis by Geiser et al. (2014) consists of a mineral salt solution, trace elements and vitamins. For our cultivations we used the highly similar PCM medium. In order to determine the effect of its different constituents on CL synthesis we further examined a PCM medium without any trace elements (TE), containing only mineral salts and vitamins (PCM-TE) and a PCM medium without vitamins (Vit), containing only mineral salts and trace elements (PCM-Vit).

When provided only mineral salts and vitamins (PCM-TE), $S$. scitamineum showed very low growth rates and no CL production (Figures 7A,B and Table 2). The addition of iron resulted in an increase of biomass concentration $\mathrm{C}_{\mathrm{CDW}}$ from $2.3 \pm 0.5 \mathrm{~g} \cdot \mathrm{L}^{-1}$ to $3.5 \pm 0.2 \mathrm{~g} \cdot \mathrm{L}^{-1}$, thus indicating a positive effect of iron addition on biomass formation. Iron was also observed to have positive effects on growth of $U$. maydis (Ardon et al., 1998). This was also reflected in slightly higher growth rates (Figure 7B). However, glucose was not completely metabolized in both media, after $240 \mathrm{~h}$ of fermentation, showing a general need of TE in the medium, for both growth and CL formation.

In PCM lacking vitamins (PCM-Vit) both biomass and CL concentrations were only slightly lower as when using the regular PCM (Table 2). Backscatter signal, DO level and growth rate curves were also comparable (Figure $7 \mathrm{C}$ ). These results are in agreement with various studies, which showed that many yeasts, including Ustilago maydis, don't need vitamins for their growth (Burkholder et al., 1944; Kurtzman and Fell, 2011). It can generally be assumed, that microorganisms showing a good growth behavior on media lacking vitamins, are able to synthesize the vitamins they need (Lindegren, 1945).

The addition of iron to these media however barely affected biomass formation, resulting in the same CDW concentrations after $240 \mathrm{~h}$ of fermentation, for both the regular PCM and PCM-Vit with or without iron. At the same time, a decrease in CL concentration was observed due to the addition of iron, from $3.8 \pm 0.6 \mathrm{~g} \cdot \mathrm{L}^{-1}$ to $1.5 \pm 0.1 \mathrm{~g} \cdot \mathrm{L}^{-1}$ for PCMVit, and from $5.1 \pm 0.3 \mathrm{~g} \cdot \mathrm{L}^{-1}$ to $1.4 \pm 0.1 \mathrm{~g} \cdot \mathrm{L}^{-1}$ for PCM, respectively. This decrease in CL concentrations may partly explain the lower backscatter levels with media containing an excess of iron (Figure 7A), despite comparable CDW at the end of fermentation. However DO levels also increase when iron is added, indicating overall lower oxygen uptake. This may be explained by the probable decrease of activity of the monooxygenases Cyp 1 (CDU25005.1) and Cyp 2 (CDS01512.1) when less CL is produced, resulting in lower oxygen demand by the cells.

Overall, the results observed with or without an excess of iron in the media, show a direct impact of its concentration on both biomass growth and CL productivity. Iron concentration is known to affect glycolipid synthesis, as described for 

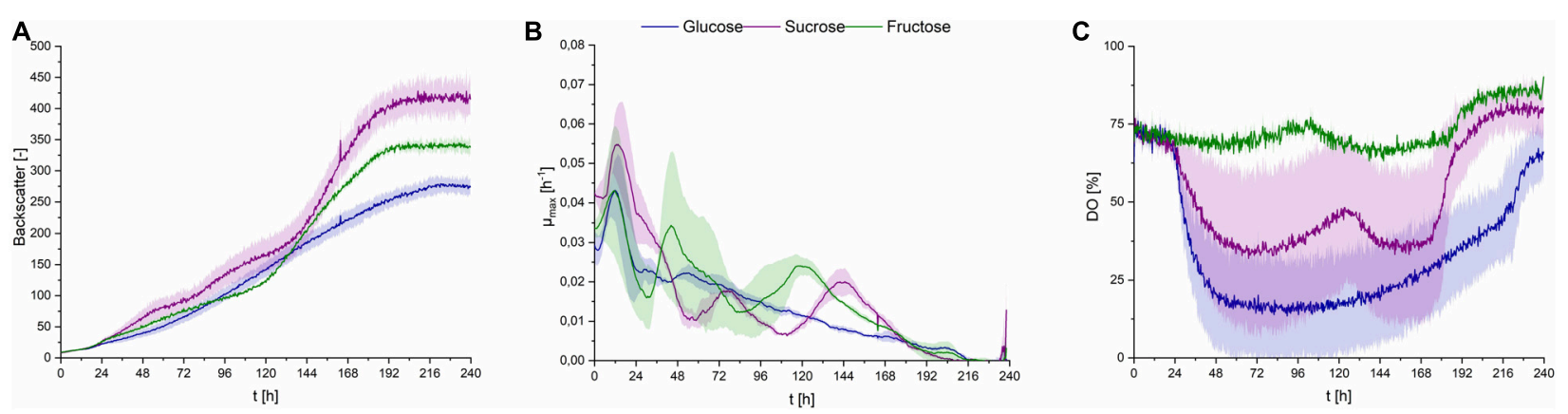

FIGURE 6 | Observations on S. scitamineum during fermentation in the micro-bioreactor system, at an inoculation pH of 2.5 , using PCM, $0.6 \mathrm{~g} \cdot \mathrm{L}^{-1}$ urea and $50 \mathrm{~g} \cdot \mathrm{L}^{-1}$ glucose, sucrose or fructose. (A) Backscatter light signal, (B) specific growth rates, and (C) DO level. Error bars are deviated from biological duplicates or triplicates $(n \geq 2)$.
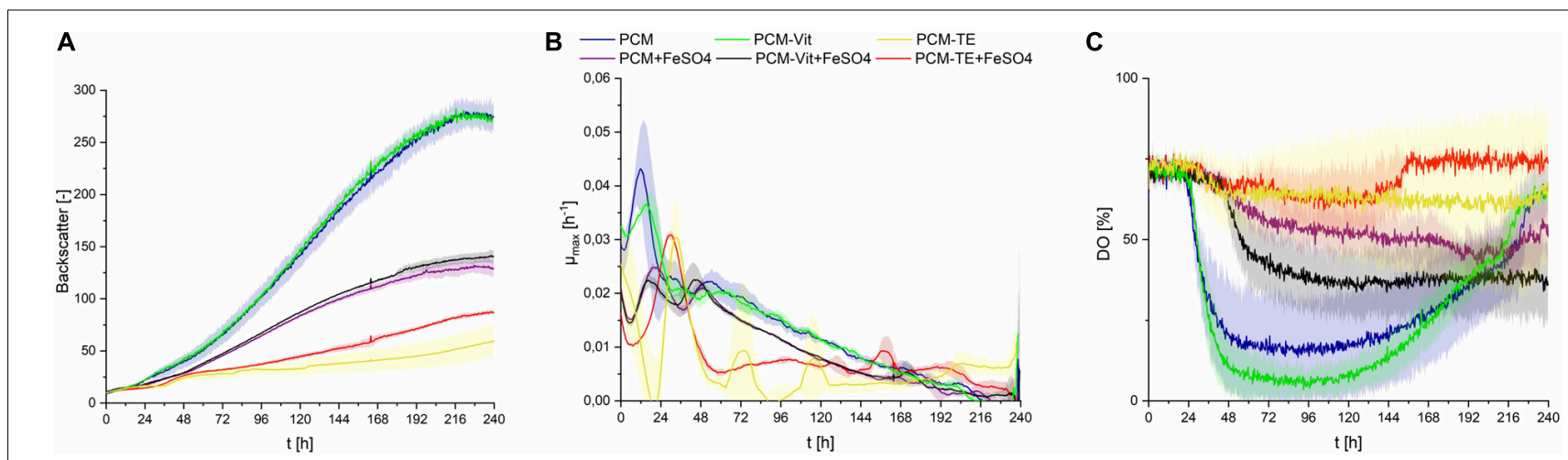

FIGURE 7 | Observations on S. scitamineum during fermentation in the micro-bioreactor system, at an inoculation $\mathrm{pH}$ of 2.5 , using $0.6 \mathrm{~g} \cdot \mathrm{L}^{-1} \mathrm{urea}$ and $50 \mathrm{~g} \cdot \mathrm{L}^{-1}$ glucose, while varying the medium composition as indicated in the diagram. $+\mathrm{FeSO}_{4}$, addition of $0.01 \mathrm{~g} \cdot \mathrm{L}^{-1} \mathrm{FeSO}$; $-\mathrm{TE}, \mathrm{PCM} \mathrm{medium}$ without trace elements; -Vit, PCM medium without vitamins. (A) Backscatter light signal, (B) specific growth rates, and (C) DO level. Error bars are deviated from biological triplicates $(n=3)$.

rhamnolipids (Guerra-Santos et al., 1984; Schmidberger et al., 2014; Shatila et al., 2020). Therefore, it is of high importance for an optimized CL production media, to determine the optimal iron concentration in the medium. We further showed that a minimal medium consisting only of mineral salts and trace elements, is sufficient for both growth of S. scitamineum and its $\mathrm{CL}$ synthesis. This is of high advantage when it comes to large scale production of CL. Vitamins are heat-labile and thus can only be sterilized via sterile filtration, as opposed to the used mineral salts and compounds supplying trace elements, that can be heat sterilized. This would save an additional sterilization step when designing a fermentation process.

\section{Formation Kinetics in Shaking Flasks and $1 \mathrm{~L}$ Bioreactors}

In order to get a better understanding on CL formation kinetics and substrate uptake, we performed a cultivation with PCM including $0.01 \mathrm{~g} \cdot \mathrm{L}^{-1} \mathrm{FeSO}_{4}$ and $50 \mathrm{~g} \cdot \mathrm{L}^{-1}$ glucose in shaking flasks (Figure 8). Based on the previously mentioned screening results, we fermented at a $\mathrm{pH}$ of 2.5 using $0.6 \mathrm{~g} \cdot \mathrm{L}^{-1}$ urea as nitrogen source. We used glucose as carbon source instead of sucrose, despite its better performance regarding CL productivity, in order to be able to further analyze growth behavior and CL synthesis in relation to nitrogen availability in the medium. Using sucrose would have added an additional factor that may affect the different growth behaviors/phases due to potentially different uptake rates of glucose and fructose, after sugar hydrolysis.

While growth rates remained in a relatively low range, with $\mu<0.1 \mathrm{~h}^{-1}$ during the first $48 \mathrm{~h}$ and $\mu<0.05 \mathrm{~h}^{-1}$ throughout the remaining growth phase, a maximum of $5.2 \pm 0.1 \mathrm{~g} \cdot \mathrm{L}^{-1}$ biomass was formed after $162 \mathrm{~h}$ of cultivation. CL was detected in the medium after urea was completely consumed ( $\sim 48 \mathrm{~h})$, and increased in concentration until glucose was entirely metabolized. Over the course of fermentation, CL concentration increased up to $8.3 \pm 1.0 \mathrm{~g} \cdot \mathrm{L}^{-1}$ after $158 \mathrm{~h}$.

In order to be able to observe DO level to gain more information on the growth behavior of S. scitamineum, and to confirm the scalability of this shaking flask cultivation, we transferred the process to the bioreactor. There we added an additional feed of glucose $\left(50 \mathrm{~g} \cdot \mathrm{L}^{-1}\right)$ after it was completely consumed $(190 \mathrm{~h})$, since a higher glucose concentration proved to be beneficial for higher CL concentrations, as shown in the screening experiments in the micro-bioreactor. All other media constituents remained the same as in the shaking flasks. Fermentation in the bioreactor was associated with extreme foam formation, which explains the high noise observed in DO values 


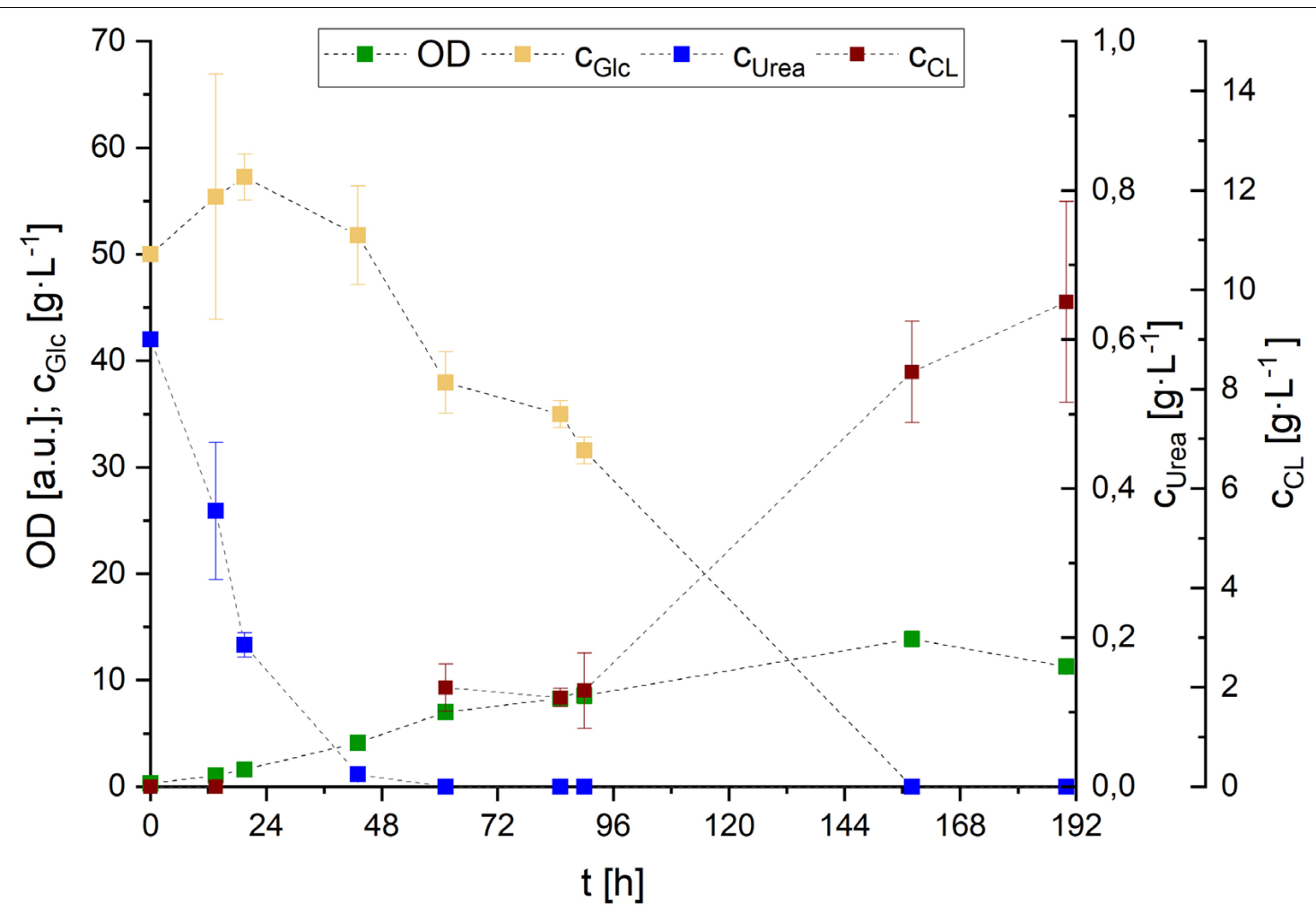

FIGURE 8 | Glucose and urea consumption, as well as OD and CL concentrations during $S$. scitamineum fermentation in $1 \mathrm{~L}$ baffled shaking flasks in PCM with $0.01 \mathrm{~g} \cdot \mathrm{L}^{-1} \mathrm{FeSO}_{4}$ at $30^{\circ} \mathrm{C}$. Error bars are deviated from biological triplicates $(n=3)$.

that was caused due to pressure fluctuations during excessive foaming phases. The general growth kinetics were similar to the results obtained in shaking flasks (Figure 9A). OD and CDW increased during the first $161 \mathrm{~h}$ of fermentation, until which glucose was completely metabolized. Urea was consumed after $90 \mathrm{~h}$ of fermentation.

The concentration levels of glucose and urea correlate with the DO oxygen level in the reactor (Figure 9B), reinforcing the hypothesis of two distinct metabolic phases, previously mentioned in section "Effect of C/N Ratio." Right after a short lag phase, glucose and urea are metabolized and OD, as well as CDW increase, while DO content decreases rapidly. To avoid oxygen limitation, stirrer speed needed to be increased from $400 \mathrm{rpm}$ up to $500 \mathrm{rpm}$ during the first $72 \mathrm{~h}$ of fermentation, corresponding to an increase in $\mathrm{k}_{\mathrm{L}}$ a value from 77 to $108 \mathrm{~h}^{-1}$ (values calculated internally). After $90 \mathrm{~h}$ of fermentation, when urea is consumed, a steady increase in DO level and thus decrease in oxygen consumption is observed, until the maximum is reached, when glucose is completely depleted. The glucose feed after $190 \mathrm{~h}$ is again reflected in an instant decrease in DO level to $20 \%$. However here, the consequent increase to the maximum occurs faster.

These results, providing additional insight into substrate consumption, further emphasize the observations described in our micro-bioreactor cultivation with different urea concentrations, supporting the hypothesis that primary growth occurs when nitrogen is present in the medium. Cells then shift to secondary growth using internal nitrogen reserves and/or accumulate tryglycerides after nitrogen limitation. The production of glycolipids may be the result of overflow metabolism for the yeast, in order to regulate the intracellular energy level, when the depletion of a factor in the medium occurs, as hypothesized for sophorose lipid production by Candida bombicola and flocculosin secretion by A. flocculosa (Davila et al., 1997; Hammami et al., 2008).

However, opposed to our cultivations in shaking flasks, low amounts of CL were detected in the reactor, prior to complete urea depletion. Nevertheless higher CL concentrations were still occurring after nitrogen limitation. The effect of nitrogen on CL synthesis is controversially discussed in literature. While many describe nitrogen starvation as a direct trigger for CL synthesis, some observations state otherwise: In various basidiomycetous yeast strains, glycolipid formation is described to be induced by nitrogen starvation (Morita et al., 2013; Zavala-Moreno et al., 2014) and CL synthesis is generally suggested to be induced by nitrogen starvation in U. maydis (Frautz et al., 1986; Teichmann et al., 2007). Expression of Cyp1, the gene involved in hydroxylation of the fatty acid in CL, even revealed that it is induced by nitrogen starvation and detected with a delay of $24 \mathrm{~h}$ (Hewald et al., 2005). Gene sequence analysis of S. scitamineum identified a highly orthologous gene CDU25005.1. However gene expression analysis have to be performed to suggest similar regulation. Interestingly, there are also reports on CL 

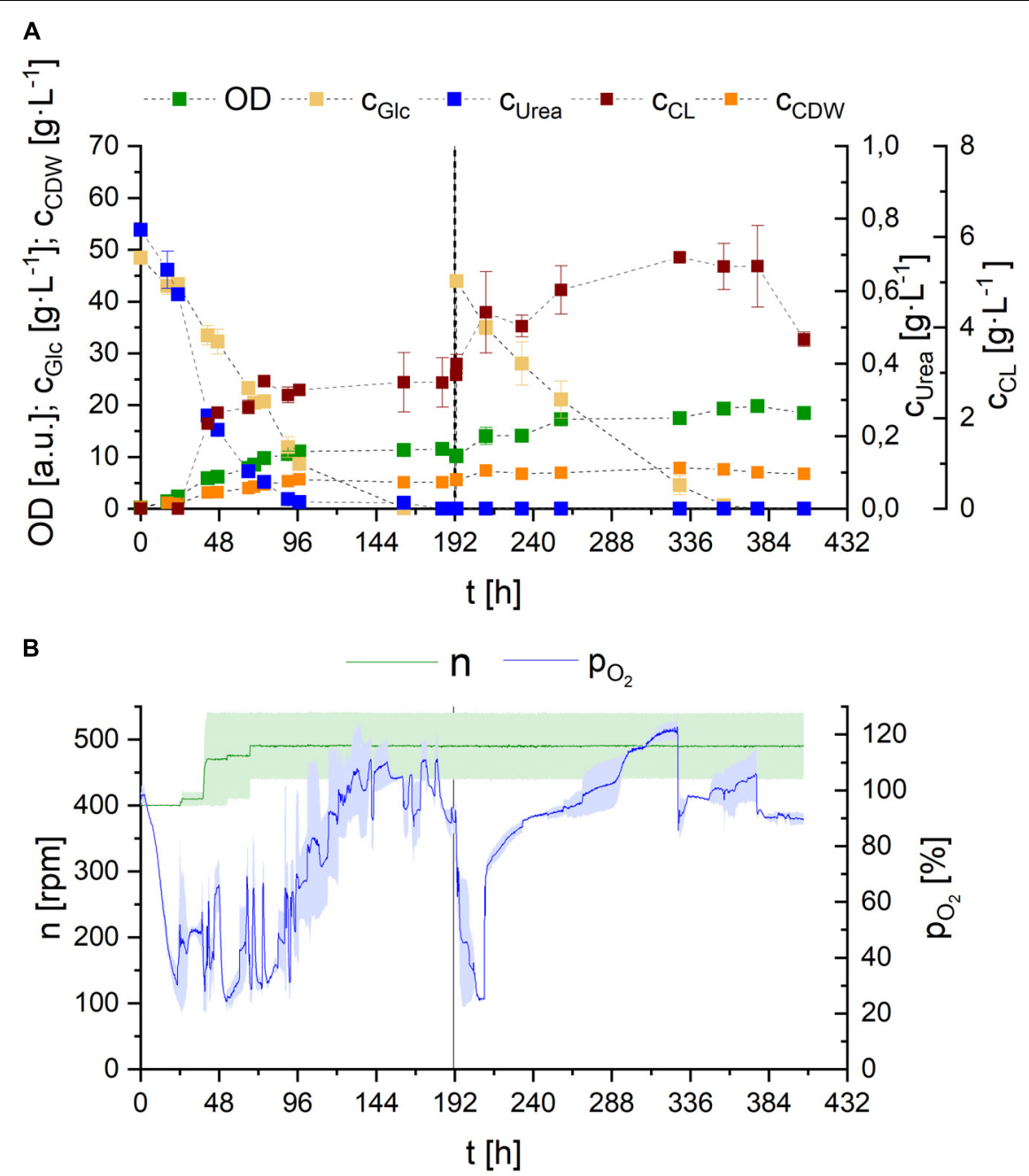

FIGURE 9 | Observations on S. scitamineum fermentation in $1 \mathrm{~L}$ bioreactor in PCM with $0.01 \mathrm{~g} \cdot \mathrm{L}^{-1} \mathrm{FeSO}_{4}$ at $30^{\circ} \mathrm{C}$. (A) Glucose and urea consumption, as well as $\mathrm{OD}, \mathrm{CDW}$, and CL concentrations; and (B) DO level and stirrer speed. The dotted line indicates glucose feed. Error bars are deviated from biological duplicates $(n=2)$ and indicated as shaded area in (B).

production by $A$. flocculosa without nitrogen limiting conditions (Hammami et al., 2008).

Therefore, based on our observed results, we suggest more investigation on other nutrient limitations in the medium, like phosphorus, that may have appeared by that course of fermentation and are also involved in triggering CL synthesis.

Looking at the overall produced CL concentrations, we observed relatively low values in the medium, compared to shaking flask results. These can be explained by the produced foam and therefrom resulting deposits on the walls of the bioreactor. While a maximum CL concentration of $5.5 \pm 0.1 \mathrm{~g} \cdot \mathrm{L}^{-1}$ was measured in the reactor, the remaining produced CL was deposited outside the liquid culture, transported by the foam. Balancing CL contained in these deposits after termination of the fermentation resulted in an overall produced CL amount of $10.6 \pm 1.2 \mathrm{~g}$, corresponding to a concentration of $17.6 \mathrm{~g} \cdot \mathrm{L}^{-1}$ in the final culture broth, at purities ranging from 85 to $93 \%$, depending on the purified fraction.
Overall higher purities were observed in the fractions obtained from the foam deposits, compared to CL directly extracted from the culture broth. Based on the screening results in sections "Effect of Carbon Source" and "Effect of Media Constituents," these concentrations could further increase, if sucrose is used as carbon source and is therefore recommended for future CL fermentations with $S$. scitamineum.

\section{MALDI-TOF MS Analysis of the Produced Cellobiose Lipid Structures}

To determine the CL structures produced by S. scitamineum, a sample of an ethanol extract was separated due to polarity on an HPTLC plate and compared to an HPTLC lane pattern of $U$. maydis (DSM 17146) CL. CL-B structures with one or two hydroxyl groups in the fatty acid chain have lower retardation factors $\mathrm{R}_{\mathrm{f}}$, compared to CL-B structures without any additional hydroxyl groups (Figure 10). $[\mathrm{M}+\mathrm{Na}]^{+}$adduct masses of 


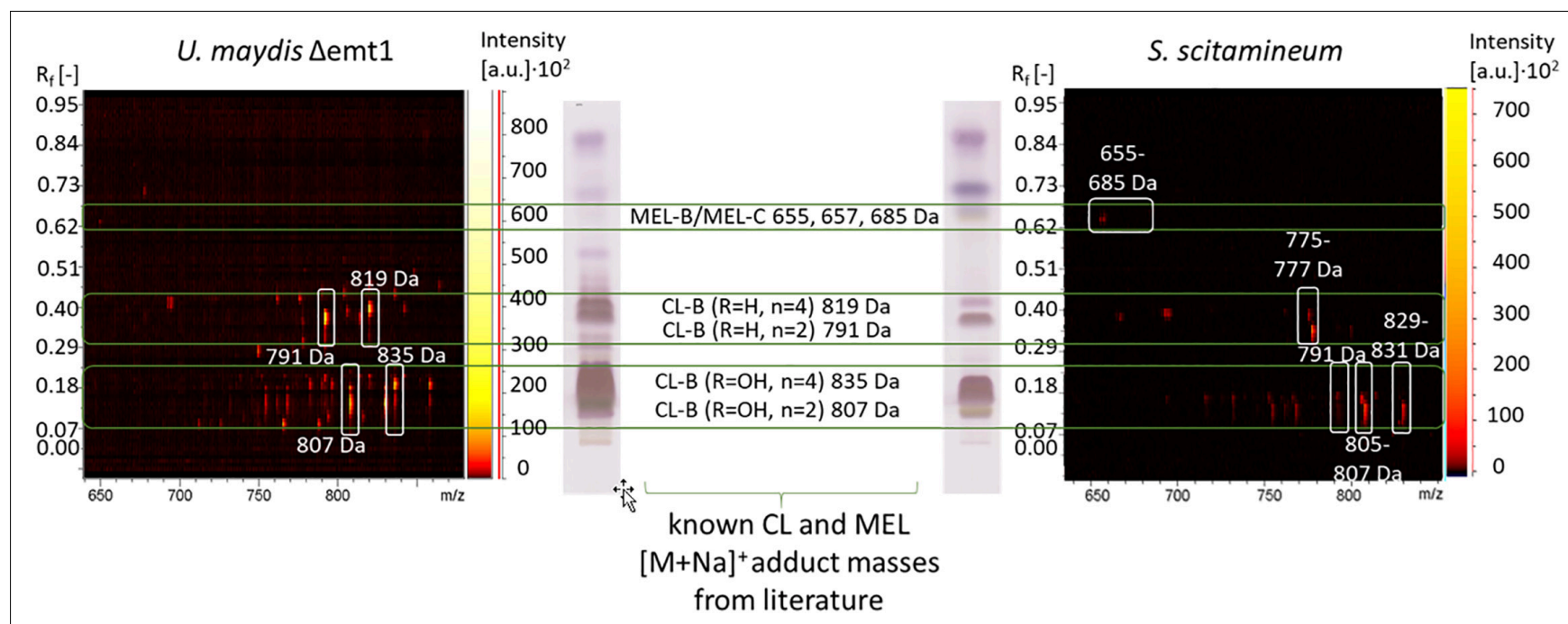

FIGURE 10 | Procedure of CL structure determination via HPTLC coupled MALDI-TOF-MS analysis. The polarity pattern of an HPTLC lane of a CL extract obtained from a S. scitamineum fermentation is compared with the polarity pattern of a CL extract from U. maydis (DSM 17146) with known CL structures. MEL structures have higher retardation factors $\mathrm{R}_{\mathrm{f}}$ due to their higher hydrophobicity. In combination with the polarity pattern, known $C L$ and MEL masses are compared with the masses of $[\mathrm{M}+\mathrm{Na}]^{+}$adducts from the 2-dimensional $\mathrm{m} / \mathrm{z}$ spectrum of the scanned lane, showing all obtained masses. Only spots with an intensity above the threshold of 500 a.u. are considered. The identified masses of CL and MEL variants produced by S. scitamineum are highlighted with white squares in the 2-dimentsional m/z spectrum. All detected masses of both TLC lanes are presented in Supplementary Tables 1, 2.

$807 \mathrm{Da}$ were identified at an $\mathrm{R}_{\mathrm{f}}$ range of $0.08-0.18$, corresponding to the CL-B variant with the acylated cellobiose moiety linked to a 2,15,16-trihydroxy-hexadecanoic acid via its $\omega$-hydroxyl group, with $n=2$ and $\mathrm{R}_{1}=\mathrm{OH}$. This detected CL-B variant corresponds to one of the structures also identified by Deinzer (2017) with another S. scitamineum strain and already known for U. maydis CL (Spoeckner et al., 1999; Teichmann et al., 2011b). Other variants with $\Delta 2 \mathrm{Da}$ each, corresponding to $805 \mathrm{Da}$ were also detected, indicating an unsaturated fatty acid chain. This could explain the slight difference in $\mathrm{R}_{\mathrm{f}}$ values between S. scitamineum CL and U. maydis CL, typically observed when the characteristic HPTLC lanes of CL extracts from both microorganisms are compared. $\mathrm{m} / \mathrm{z}$ differences of $\Delta 16 \mathrm{Da}$ were attributed to additional hydroxyl groups. Masses of $791 \mathrm{Da}$ were also detected, however, the absence of the hydroxyl group at $\mathrm{R}_{1}$ should have resulted in higher $\mathrm{R}_{\mathrm{f}}$ values here, as can be seen in the $U$. maydis TLC lane (0.21-0.4). With $\mathrm{R}_{\mathrm{f}}$ values in the same range as the masses with $807 \mathrm{Da}$, the absence of the hydroxyl group in this case has to be at another position than $\mathrm{R}_{1}$. Differences of $\Delta 28$ Da correspond to the length of the acetyl chain $n=2$ or 4 and result in the values of the less polar variants with 835 and $819 \mathrm{Da}$ produced by $U$. maydis. These masses were not detected in the TLC lane of S. scitamineum, however a polar variant with 829$831 \mathrm{Da}$ was identified in high quantities, at the same $\mathrm{R}_{\mathrm{f}}$ range of the $835 \mathrm{Da}$ variant from $U$. maydis. The difference of $4 \mathrm{Da}$ here may be explained by the presence of a di-unsaturated fatty acid, which again would explain slight differences in $R_{f}$ values between S. scitamineum CL and U. maydis CL TLC lanes. A less polar variant with 775-777 Da was detected in the $\mathrm{Rf}$ range of the CL-B variant with $\mathrm{R}_{1}=\mathrm{H}$ and $n=2(791 \mathrm{Da})$ of $U$. maydis. The mass difference of $\Delta 14 \mathrm{Da}$ of the $777 \mathrm{Da}$ variant may indicate the presence of a C15 fatty acid chain in this more hydrophobic
CL variant of S. scitamineum, while the difference of $\Delta 16 \mathrm{Da}$ of the $775 \mathrm{Da}$ variant would be attributed to a missing hydroxyl group. This may be an indication of a variant without a hydroxyl group at the C6 fatty acid, as was desccribed for $\Delta$ uhd 1 mutants of $U$. maydis, or a missing hydroxyl group at the C16 fatty acid, as was described for $\Delta$ cyp 2 mutants of $U$. maydis (Teichmann, 2009). Both hypothetical variants would result in a slight change in $\mathrm{R}_{\mathrm{f}}$ values of the detected TLC lanes of CL samples from $S$. scitamineum compared to the CL samples from U. maydis, as is typically observed here. However for a more detailed structure determination of these detected CL masses, further analyses like MSMS need to be done.

Several other masses in the mass spectrum range between known CL and MEL structures (685 - $775 \mathrm{Da})$ were also detected, however not yet identified (see detailed in Supplementary Table S1). We further identified less polar structures with $\mathrm{m} / \mathrm{z}$ of $655 \mathrm{Da}, 657$ and $685 \mathrm{Da}$ that correspond to known MEL-B/MELC structures (Deinzer, 2017; Beck et al., 2019).

\section{CONCLUSION}

We here report the first systematic description of factors affecting CL synthesis by S. scitamineum leading to high CL concentrations, up to $17.6 \mathrm{~g} \cdot \mathrm{L}^{-1}$ in a $1 \mathrm{~L}$ bioreactor. $\mathrm{A} \mathrm{pH}$ of 2.5 , a $\mathrm{C} / \mathrm{N}$ ratio of $83.8 \mathrm{~mol}_{\mathrm{C}} \cdot \mathrm{mol}_{\mathrm{N}}{ }^{-1}$ using $0.6 \mathrm{~g} \cdot \mathrm{L}^{-1}$ urea as nitrogen source and sucrose as carbon source proved to be optimal for CL synthesis, while vitamins were not essential for glycolipid production by $S$. scitamineum. Nitrogen and iron concentrations, however, have a major effect on both biomass growth and CL formation and should be considered for further media optimization. 
Via a TLC coupled MALDI-TOF MS method we identified the produced CL structures as a mixture of different CL-B variants. which correspond to some of the known CL structures that are produced by $U$. maydis. This is explained by the highly similar CL synthesis gene cluster we identified by BLAST analysis in the published genome sequence data of S. scitamineum SscI8. Furthermore, the sequences of the identified CL-biosynthesis cluster can be used in future studies to complement the presented work by gene expression data to achieve further insights into the regulation of the CL biosynthesis in S. scitamineum.

\section{DATA AVAILABILITY STATEMENT}

Publicly available datasets were analyzed in this study. This data can be found here: ASM90000236v1.

\section{AUTHOR CONTRIBUTIONS}

AO contributed conception and design of the study, analysis and interpretation of the data, and wrote the first draft of the manuscript. NW contributed with gene sequence analysis and interpretation. ZS assisted with the experimental work. SZ acquired grants and supervised $\mathrm{AO}$ in her work, and contributed to scientific arrangement and manuscript revision. All authors read and approved the submitted version.

\section{REFERENCES}

Ageitos, J. M., Vallejo, J. A., Veiga-Crespo, P., and Villa, T. G. (2011). Oily yeasts as oleaginous cell factories. Appl. Microbiol. Biotechnol. 90, 1219-1227. doi: 10.1007/s00253-011-3200-z

Ardon, O., Nudelman, R., Caris, C., Libman, J., Shanzer, A., Chen, Y., et al. (1998). Iron Uptake in Ustilago maydis: tracking the iron path. J. Bacteriol. 180, 2021-2026. doi: 10.1128/jb.180.8.2021-2026.1998

Beck, A., Haitz, F., Grunwald, S., Preuss, L., Rupp, S., and Zibek, S. (2019). Influence of microorganism and plant oils on the structure of mannosylerythritol lipid (MEL) biosurfactants revealed by a novel thin layer chromatography mass spectrometry method. J. Industr. Microbiol. Biotechnol. 46, 1191-1204. doi: 10.1007/s10295-019-02194-2

Braithwaite, K. S., Bakkeren, G., Croft, B. J., and Brumbley, S. M. (2004). Genetic variation in a worldwide collection of the sugarcane smut fungus Ustilago scitaminea. Proc. Aust. Soc. Sugar Cane Technol. 26, 1-9.

Brakhage, A. A. (2013). Regulation of fungal secondary metabolism. Nat. Rev. Microbiol. 11, 21-32. doi: 10.1038/nrmicro2916

Burkholder, P. R., McVeigh, I., and Moyer, D. (1944). Studies on some growth factors of yeasts1. J. Bacteriol. 48, 385-391. doi: 10.1128/jb.48.4.385-391.1944

Cheng, Y., McNally, D. J., Labbé, C., Voyer, N., Belzile, F., and Bélanger, R. R. (2003). Insertional mutagenesis of a fungal biocontrol agent led to discovery of a rare cellobiose lipid with antifungal activity. Appl. Environ. Microbiol. 69, 2595-2602. doi: 10.1128/AEM.69.5.2595-2602.2003

Davila, A. M., Marcha, R., and Vandecasteele, J. P. (1997). Sophorose lipid fermentation with differential substrate supply for growth and production phases. Appl. Microbio. Biotechnol. 47, 496-501. doi: 10.1007/s002530050962

Deinzer, H.-T. (2017). Charakterisierung Metabolisch Veränderter Glycolipide in Ustilago maydis. Marburg: University of Marburg.

DSMZ, (2020). List of Media for Microorganisms. Available at: https: //www.dsmz.de/collection/catalogue/microorganisms/culture-technology/ list-of-media-for-microorganisms (accessed June 8, 2020).

Dutheil, J. Y., Mannhaupt, G., Schweizer, G., Sieber, M. K. C., Münsterkötter, M., Güldener, U., et al. (2016). A tale of genome compartmentalization: the

\section{FUNDING}

This work was partly funded by a ph.D.-scholarship from the German Federal Environmental Foundation (DBU) AZ: $80017 / 333$, by grants from the Federal Ministry of Education and Research (031B0469P) and the device for micro-fermentation was funded by (031B0371A).

\section{ACKNOWLEDGMENTS}

We would like to acknowledge the effort of Alexander Beck and Fabian Haitz invested in commenting and discussing this work. Thank you for your fruitful input to this manuscript. AO would further like to thank Profs. Drs. Steffen Rupp and Günter Tovar for their support during her Ph.D. research.

\section{SUPPLEMENTARY MATERIAL}

The Supplementary Material for this article can be found online at: https://www.frontiersin.org/articles/10.3389/fbioe. 2020.555647/full\#supplementary-material

evolution of virulence clusters in smut fungi. Genome Biol. Evol. 8, 681-704. doi: $10.1093 / \mathrm{gbe} / \mathrm{evw026}$

Eveleigh, D., and Dateo, G. P. (1964). Fungal metabolism of complex glycosides: ustilagic acid. J. Biol. Chem. 239, 839-844.

Frautz, B., Lang, S., and Wagner, F. (1986). Formation of cellobiose lipids by growing and resting cells of Ustilago maydis. Biotechnol. Lett. 8, 757-762. doi: 10.1007/BF01020817

Funke, M., Diederichs, S., Kensy, F., Müller, C., and Büchs, J. (2009). The baffled microtiter plate: increased oxygen transfer and improved online monitoring in small scale fermentations. Biotechnol. Bioeng. 103, 1118-1128. doi: 10.1002/bit. 22341

Geiser, E., Wiebach, V., Wierckx, N., and Blank, L. M. (2014). Prospecting the biodiversity of the fungal family Ustilaginaceae for the production of value-added chemicals. Fungal Biol. Biotechnol. 1:15. doi: 10.1186/s40694-0140002-y

Golubev, W. I., Kulakovskaya, T. V., Shashkov, A. S., Kulakovskaya, E. V., and Golubev, N. V. (2008). Antifungal cellobiose lipid secreted by the epiphytic yeast Pseudozyma graminicola. Microbiology 77, 171-175. doi: 10. 1134/S0026261708020082

Guerra-Santos, L., Käppeli, O., and Fiechter, A. (1984). Pseudomonas aeruginosa biosurfactant production in continuous culture with glucose as carbon source. Appl. Environ. Microbiol. 48, 301-305. doi: 10.1128/aem.48.2.301-305.1984

Günther, M. (2014). Mikrobielle Synthese, Aufarbeitung, Modifizierung und Tensideigenschaften von Mannosylerythritollipiden und Cellobioselipiden. Stuttgart: University of Stuttgart.

Günther, M., Zibek, S., Hirth, T., and Rupp, S. (2010). Synthese und optimierung von cellobioselipiden und mannosylerythritollipiden. Chem. Ingenieur Techn. 82, 1215-1221. doi: 10.1002/cite.201000078

Hammami, W., Labbe, C., Chain, F., Mimee, B., and Belanger, R. R. (2008). Nutritional regulation and kinetics of flocculosin synthesis by Pseudozyma flocculosa. Appl. Microbiol. Biotechnol. 80, 307-315. doi: 10.1007/s00253-0081541-z

Hartmann, S. K., Stockdreher, Y., Wandrey, G., Hosseinpour Tehrani, H., Zambanini, T., Meyer, A. J., et al. (2018). Online in vivo monitoring of cytosolic 
NAD redox dynamics in Ustilago maydis. Biochim. Biophys. Acta Bioenerget. 1859, 1015-1024. doi: 10.1016/j.bbabio.2018.05.012

Haskins, R. H. (1950). Biochemistry of the Ustilaginales: preliminary cultural studies of Ustilago zeae. Can. J. Res. 28c, 213-223. doi: 10.1139/cjr50c-012

Haskins, R. H., and Thorn, J. A. (1951). Biochemistry of the Ustilaginales: VII. Antibiotic activity of ustilagic acid. Can. J. Bot. 29, 585-592. doi: 10.1139/b51-046

Hewald, S., Josephs, K., and Bolker, M. (2005). Genetic analysis of biosurfactant production in Ustilago maydis. Appl. Environ. Microbiol. 71, 3033-3040. doi: 10.1128/AEM.71.6.3033-3040.2005

Hewald, S., Linne, U., Scherer, M., Marahiel, M. A., Kamper, J., and Bolker, M. (2006). Identification of a gene cluster for biosynthesis of mannosylerythritol lipids in the Basidiomycetous fungus Ustilago maydis. Appl. Environ. Microbiol. 72, 5469-5477. doi: 10.1128/AEM.00506-06

Imura, T., Yamamoto, S., Yamashita, C., Taira, T., Minamikawa, H., Morita, T., et al. (2014). Aqueous gel formation from sodium salts of cellobiose lipids. J. Oleo Sci. 63, 1005-1010. doi: 10.5650/jos.ess 14104

Klement, T., Milker, S., Jäger, G., Grande, P. M., Domínguez de María, P., and Büchs, J. (2012). Biomass pretreatment affects Ustilago maydis in producing itaconic acid. Microb. Cell Fact. 11:43. doi: 10.1186/1475-2859-11-43

Kulakovskaya, E. V., Golubev, V. I., and Kulaev, I. S. (2006). Extracellular antifungal glycolipids of Cryptococcus humicola yeasts. Dokl. Biol. Sci. 410, 393-395. doi: $10.1134 / \mathrm{S} 0012496606050140$

Kulakovskaya, E. V., Kulakovskaya, T. V., Golubev, V. I., Shashkov, A. S., Grachev, A. A., and Nifantiev, N. E. (2007). Fungicidal activity of cellobiose lipids from culture broth of yeast Cryptococcus humicola and Pseudozyma fusiformata. Russ. J. Bioorg. Chem. 33, 156-160. doi: 10.1134/S1068162007010189

Kulakovskaya, T. V., Shashkov, A. S., Kulakovskaya, E. V., and Golubev, W. I. (2005). Ustilagic acid secretion by Pseudozyma fusiformata strains. FEMS Yeast Res. 5, 919-923. doi: 10.1016/j.femsyr.2005.04.006

Kurtzman, C. P., and Fell, J. W. (2011). "Summary of species characteristics," in The Yeasts, a Taxonomic Study, eds C. P. Kurtzman, J. W. Fell, and T. Boekhout, (Amsterdam: Elsevier), 223-277. doi: 10.1016/b978-0-444-52149-1.00165-8

Lindegren, C. C. (1945). YEAST GENETICS 1: life cycles, cytology, hybridization, vitamin synthesis, and adaptive enzymes. Bacteriol. Rev. 9, 111-170.

Liu, Y., Koh, C. M. J., and Ji, L. (2011). Bioconversion of crude glycerol to glycolipids in Ustilago maydis. Bioresour. Technol. 102, 3927-3933. doi: 10.1016/ j.biortech.2010.11.115

Madeira, F., Park, Y. M., Lee, J., Buso, N., Gur, T., Madhusoodanan, N., et al. (2019). The EMBL-EBI search and sequence analysis tools APIs in 2019. Nucleic Acids Res. 47, W636-W641. doi: 10.1093/nar/gkz268

Morita, T., Fukuoka, T., Imura, T., and Kitamoto, D. (2013). Accumulation of cellobiose lipids under nitrogen-limiting conditions by two ustilaginomycetous yeasts, Pseudozyma aphidis and Pseudozyma hubeiensis. FEMS Yeast Res. 13, 44-49. doi: 10.1111/1567-1364.12005

Morita, T., Fukuoka, T., Imura, T., and Kitamoto, D. (2015). Mannosylerythritol lipids: production and applications. J. Oleo Sci. 64, 133-141. doi: 10.5650/jos. ess 14185

Morita, T., Ishibashi, Y., Fukuoka, T., Imura, T., Sakai, H., Abe, M., et al. (2009a). Production of glycolipid biosurfactants, mannosylerythritol lipids, by a smut fungus, Ustilago scitaminea NBRC 32730. Biosci. Biotechnol. Biochem. 73, 788792. doi: $10.1271 / \mathrm{bbb} .80901$

Morita, T., Ishibashi, Y., Fukuoka, T., Imura, T., Sakai, H., Abe, M., et al. (2009b). Production of glycolipid biosurfactants, mannosylerythritol lipids, using sucrose by fungal and yeast strains, and their interfacial properties. Biosci. Biotechnol. Biochem. 73, 2352-2355. doi: 10.1271/bbb.90439

Morita, T., Ishibashi, Y., Fukuoka, T., Imura, T., Sakai, H., Abe, M., et al. (2011). Production of glycolipid biosurfactants, cellobiose lipids, by Cryptococcus humicola JCM 1461 and their interfacial properties. Biosci. Biotechnol. Biochem. 75, 1597-1599. doi: 10.1271/bbb.110036

Peros, J.-P., Piombo, G., and Dumas, J.-C. (1986). Carbohydrate metabolism of the sugarcane smut fungus Ustilago scitaminea. Curr. Microbiol. 13, 303-306. doi: $10.1007 / \mathrm{bf} 01577196$

Puchkov, E. O., Zähringer, U., Lindner, B., Kulakovskaya, T. V., Seydel, U., and Wiese, A. (2002). The mycocidal, membrane-active complex of Cryptococcus humicola is a new type of cellobiose lipid with detergent features. Biochim. Biophys. Acta 1558, 161-170. doi: 10.1016/s0005-2736(01)00428-x

Que, Y., Xu, L., Wu, Q., Liu, Y., Ling, H., Liu, Y., et al. (2014). Genome sequencing of Sporisorium scitamineum provides insights into the pathogenic mechanisms of sugarcane smut. BMC Genom. 15:996. doi: 10.1186/1471-2164-15-996

Roxburgh, J. M., and Spencer, J. F. T. (1954). Factors affecting the production of ustilagic acid by Ustilago zeae. Agric. Food Chem. 2, 1121-1124. doi: 10.1021/ jf60042a007

Samorski, M., Müller-Newen, G., and Büchs, J. (2005). Quasi-continuous combined scattered light and fluorescence measurements: a novel measurement technique for shaken microtiter plates. Biotechnol. Bioeng. 92, 61-68. doi: 10. 1002/bit.20573

Schmidberger, A., Henkel, M., Hausmann, R., and Schwartz, T. (2014). Influence of ferric iron on gene expression and rhamnolipid synthesis during batch cultivation of Pseudomonas aeruginosa PAO1. Appl. Microbiol. Biotechnol. 98, 6725-6737. doi: 10.1007/s00253-014-5747-y

Shatila, F., Diallo, M. M., Şahar, U., Ozdemir, G., and Yalçın, H. T. (2020). The effect of carbon, nitrogen and iron ions on mono-rhamnolipid production and rhamnolipid synthesis gene expression by Pseudomonas aeruginosa ATCC 15442. Arch. Microbiol. 202, 1407-1417. doi: 10.1007/s00203-020-01857-4

Spoeckner, S., Wray, V., Nimtz, M., and Lang, S. (1999). Glycolipids of the smut fungus Ustilago maydis from cultivation on renewable resources. Appl. Microbiol. Biotechnol. 51, 33-39. doi: 10.1007/s002530051359

Taniguti, L. M., Schaker, P. D. C., Benevenuto, J., Peters, L. P., Carvalho, G., Palhares, A., et al. (2015). Complete genome sequence of Sporisorium scitamineum and biotrophic interaction transcriptome with sugarcane. PLoS One 10:e0129318. doi: 10.1371/journal.pone.0129318

Teichmann, B. (2009). Das Cellobioselipid Ustilaginsäure aus Ustilago maydis: Biosynthese und Transkriptionelle Regulation, Ph. D thesis, Universität Marburg, Marburg.

Teichmann, B., Labbe, C., Lefebvre, F., Bolker, M., Linne, U., and Belanger, R. R. (2011a). Identification of a biosynthesis gene cluster for flocculosin a cellobiose lipid produced by the biocontrol agent Pseudozyma flocculosa. Mol. Microbiol. 79, 1483-1495. doi: 10.1111/j.1365-2958.2010.07533.x

Teichmann, B., Lefebvre, F., Labbe, C., Bolker, M., Linne, U., and Belanger, R. R. (2011b). Beta hydroxylation of glycolipids from Ustilago maydis and Pseudozyma flocculosa by an NADPH-dependent beta-hydroxylase. Appl. Environ. Microbiol. 77, 7823-7829. doi: 10.1128/AEM.05822-11

Teichmann, B., Linne, U., Hewald, S., Marahiel, M. A., and Bolker, M. (2007). A biosynthetic gene cluster for a secreted cellobiose lipid with antifungal activity from Ustilago maydis. Mol. Microbiol. 66, 525-533. doi: 10.1111/j.1365-2958. 2007.05941.x

Teichmann, B., Liu, L., Schink, K. O., and Bolker, M. (2010). Activation of the ustilagic acid biosynthesis gene cluster in Ustilago maydis by the $\mathrm{C} 2 \mathrm{H} 2$ zinc finger transcription factor Rua1. Appl. Environ. Microbiol. 76, 2633-2640. doi: 10.1128/AEM.02211-09

Voll, A., Klement, T., Gerhards, G., Büchs, J., and Marquardt, W. (2012). Metabolic modelling of itaconic acid fermentation with Ustilago Maydis. Chem. Eng. Trans. 27, 367-372.

Zavala-Moreno, A., Arreguin-Espinosa, R., Pardo, J. P., Romero-Aguilar, L., and Guerra-Sánchez, G. (2014). Nitrogen source affects glycolipid production and lipid accumulation in the Phytopathogen fungus Ustilago maydis. AiM 04, 934-944. doi: 10.4236/aim.2014.413104

Conflict of Interest: The authors declare that the research was conducted in the absence of any commercial or financial relationships that could be construed as a potential conflict of interest.

Copyright $\odot 2020$ Oraby, Werner, Sungur and Zibek. This is an open-access article distributed under the terms of the Creative Commons Attribution License (CC BY). The use, distribution or reproduction in other forums is permitted, provided the original author(s) and the copyright owner(s) are credited and that the original publication in this journal is cited, in accordance with accepted academic practice. No use, distribution or reproduction is permitted which does not comply with these terms. 